\title{
Hippocampal $\mu$-opioid receptors on GABAergic neurons mediate stress-induced impairment of memory retrieval
}

\author{
Mei-Mei Shi ${ }^{1,2} \cdot$ Ka-Min Fan ${ }^{1} \cdot$ Yan-Ning Qiao ${ }^{1}$ Jin-Hui Xu' ${ }^{1}$ Li-Juan Qiu ${ }^{1} \cdot$ Xiao Li $^{1} \cdot$ Ying Liu $^{1} \cdot$ Zhao-Qiang Qian $^{1}$. \\ Chun-Ling Wei ${ }^{1} \cdot$ Jing Han ${ }^{1} \cdot$ Juan Fan $^{3} \cdot$ Ying-Fang Tian ${ }^{3} \cdot$ Wei Ren ${ }^{1,2} \cdot$ Zhi-Qiang Liu $^{1}$
}

Received: 1 November 2018 / Revised: 18 April 2019 / Accepted: 29 April 2019 / Published online: 29 May 2019

(c) The Author(s) 2019. This article is published with open access

\begin{abstract}
Stressful life events induce abnormalities in emotional and cognitive behaviour. The endogenous opioid system plays an essential role in stress adaptation and coping strategies. In particular, the $\mu$-opioid receptor $(\mu \mathrm{R})$, one of the major opioid receptors, strongly influences memory processing in that alterations in $\mu \mathrm{R}$ signalling are associated with various neuropsychiatric disorders. However, it remains unclear whether $\mu \mathrm{R}$ signalling contributes to memory impairments induced by acute stress. Here, we utilized pharmacological methods and cell-type-selective/non-cell-type-selective $\mu \mathrm{R}$ depletion approaches combined with behavioural tests, biochemical analyses, and in vitro electrophysiological recordings to investigate the role of hippocampal $\mu \mathrm{R}$ signalling in memory-retrieval impairment induced by acute elevated platform (EP) stress in mice. Biochemical and molecular analyses revealed that hippocampal $\mu$ Rs were significantly activated during acute stress. Blockage of hippocampal $\mu$ Rs, non-selective deletion of $\mu$ Rs or selective deletion of $\mu$ Rs on GABAergic neurons $\left(\mu \mathrm{R}_{\mathrm{GABA}}\right)$ reversed EP-stress-induced impairment of memory retrieval, with no effect on the elevation of serum corticosterone after stress. Electrophysiological results demonstrated that stress depressed hippocampal GABAergic synaptic transmission to CA1 pyramidal neurons, thereby leading to excitation/inhibition (E/I) imbalance in a $\mu \mathrm{R}_{\mathrm{GABA}}$-dependent manner. Pharmaceutically enhancing hippocampal $\mathrm{GABA}_{\mathrm{A}}$ receptor-mediated inhibitory currents in stressed mice restored their memory retrieval, whereas inhibiting those currents in the unstressed mice mimicked the stress-induced impairment of memory retrieval. Our findings reveal a novel pathway in which endogenous opioids recruited by acute stress predominantly activate $\mu \mathrm{R}_{\mathrm{GABA}}$ to depress GABAergic inhibitory effects on CA1 pyramidal neurons, which subsequently alters the E/I balance in the hippocampus and results in impairment of memory retrieval.
\end{abstract}

These authors contributed equally: Mei-Mei Shi, Ka-Min Fan, YanNing Qiao

Supplementary information The online version of this article (https:// doi.org/10.1038/s41380-019-0435-z) contains supplementary material, which is available to authorized users.

Wei Ren

renwei@snnu.edu.cn

$\bowtie$ Zhi-Qiang Liu

liuzhiqiang@snnu.edu.cn

1 MOE Key Laboratory of Modern Teaching Technology, Center for Teacher Professional Ability Development, Xi'an, China

2 School of Psychology, Shaanxi Normal University, Xi' an, China

3 College of Life Sciences, Shaanxi Normal University, No.199, South Chang'an Rd., Xi' an 710062, China

\section{Introduction}

Severe or prolonged stressful life events impair cognitive function by influencing a series of brain regions in a complex manner [1,2]. The hippocampus, a structure implicated in learning and memory processes, is particularly vulnerable to stressful experiences. Exposure to acute stress consistently disrupts hippocampal-dependent memory retrieval immediately afterward [3, 4]. Extensive studies have demonstrated that elevated glucocorticoid hormones during stress impair memory retrieval by modulating glutamatergic synaptic plasticity at the Schaffer collateral/commissural-CA1 synapses in the hippocampus, likely through inhibiting LTP induction or facilitating LTD [4-8]. Nevertheless, the magnitude of impairment by glucocorticoids does not match the impact of stress on memory [9], indicating that multiple neural mechanisms, not limited to the effects of glucocorticoids, may underlie stress-induced impairment of memory retrieval. 
In addition to glucocorticoid hormones, acute stress also elicits the engagement of various neurotransmitters and neuromodulators, including monoamines, endogenous opioid peptides (EOPs), endocannabinoids, neuropeptide $\mathrm{Y}$, oxytocin, and sex hormones, which interact with glucocorticoid hormones to manipulate responses to stress $[9,10]$. Exposure to stress rapidly increases the release of enkephalin, $\beta$-endorphin, dynorphin, and nociceptin in brain regions closely related to emotion and cognition [11, 12]. Through activation of the three major opioid receptors that are densely expressed in the central nervous system $(\mu, \delta$, and $\kappa$ ), EOPs actively participate in the modulation of a series of cognitive, emotional, cardiovascular, and gastroenterological responses and enable adaptation to stress $[13,14]$. However, whether the endogenous opioid system (EOS) plays an essential role in stress-induced impairments of learning and memory remains completely unknown.

Area CA1, a subfield of the hippocampus that receives substantial input from layer III of the entorhinal cortex via direct temporoammonic projections and Schaffer collaterals input from $\mathrm{CA} 3$, is necessary for the rapid formation and retrieval of spatial memory [15]. Opioid receptors are abundantly expressed on interneurons in CA1 [16]. Exogenously activating the CA1 $\mu$-opioid receptors ( $\mu$ Rs) reduces the firing rate and neurotransmitter release rate of the interneurons, which then disinhibit the pyramidal neurons, resulting in excitation/inhibition (E/I) imbalance [17-20]. Bias from the $\mathrm{E} / \mathrm{I}$ balance could further disrupt the input-output functions of hippocampal synaptic circuits [21] and might impair spatial learning and memory. We thus hypothesize that, in addition to the direct effects of glucocorticoids on hippocampal glutamatergic synaptic plasticity, increased EOPs may also regulate stress-induced impairment of memory retrieval by inhibiting GABAergic interneurons in CA1. Such a regulatory mechanism of EOPs in local inhibitory circuitry in the hippocampus would be a novel pathway underpinning stress-induced memory impairments.

\section{Materials and methods}

\section{Animals}

Male C57BL/6J (from the Model Animal Research Center of Nanjing University, China) and mutant mice (8-12 weeks old) weighing 18-24 g were used in experiments. All experiments were carried out in accordance with the requirements of the Chinese Council on Animal Care and approved by the Animal Care Committee of Shaanxi Normal University. Mice were housed in groups of 4 in individually ventilated cages and maintained at $22 \pm 2{ }^{\circ} \mathrm{C}$ and $55 \pm 5 \%$ relative humidity under a 12:12-h light/dark schedule. Food and water were available ad libitum. The animals were handled for 5 days ( 3 min each day) before the behavioural experiments. All behavioural experiments and blood or tissue sample collection were conducted between 10:00 am and 3:00 pm. Animals were randomly assigned to groups without pre-estimating sample size.

Oprm1-floxed mice were constructed by inserting two loxP sites flanking exons 2-3 of the Oprml gene. The Oprm1 gene targeting vector was constructed with BAC retrieval methods. The Oprml gene locus was retrieved from BAC clones obtained from a mouse C57BL/6 genomic library using a retrieval vector containing 2 homologous arms. The targeting vector included the $5^{\prime}$ region, a loxP site, the coding sequence of exons $2-3$, a neomycin phosphotransferase expression (Neo) cassette (Frt-Neo-Frt), a second loxP site, and the $3^{\prime}$ region. After digestion by AscI, the linearized vectors were electroporated into C57BL/6 embryonic stem (ES) cells, and the targeted clones were selected with Southern blot analysis. Once homologous recombination was completed, the Sacl-digested-fragment and the EcoRI-digested-fragment would turn from 16.3 to $10.4 \mathrm{~kb}$ and from 15.1 to $10.2 \mathrm{~kb}$, respectively, as detected with probes. Random integrations were negatively selected with diphtheria toxin A (DTA), and the positive clones were screened with G418. Selected ES clones were injected into blastocysts of C57BL/6 mice to generate chimeric mice. Germ-line transmission was obtained when chimaeras were crossed to B6 breeders. The Frt-Neo-Frt cassette was deleted by crossing with a Flp recombinase mouse. Floxed and wild-type Oprml alleles in the offspring were detected by PCR using the following primers: Oprm1-A1 LoxP-F: 5'-GGTTAGAGTTAGGAGAATCAGGAGTTCAAG-3'; Oprm1-A2 LoxP-R: 5'-GTGAGAGTTGATGTTTGTAA TTGAGTGCC- $3^{\prime}$, product $214 \mathrm{bp}$ (wild type) and $268 \mathrm{bp}$ (floxed); Oprm1-Frt-F 5'-TAGTGTTAGGAAGATGTGCC

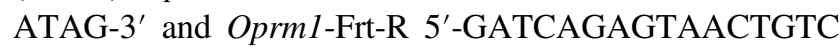
TTGGCTAC- $3^{\prime}$, product 198 bp (wild type) and 328 bp (floxed). The Oprml-floxed mice were then crossed to CMV-Cre mice [22] (from the Model Animal Research Center of Nanjing University, China) or mice expressing Cre in a cell-type-specific manner (including GFAPCreERT2 mice [23], vGlut1-iCreERT2 mice and Gad2iCreERT2 mice [24] from Beijing Biocytogen, China) as described previously in order to target Oprml in all tissues, astroglial cells $\left(\mu \mathrm{R}_{\mathrm{Astro}}\right)$, glutamatergic neurons $\left(\mu \mathrm{R}_{\mathrm{Glut}}\right)$ or GABAergic neurons $\left(\mu \mathrm{R}_{\mathrm{GABA}}\right)$, respectively. The Oprm1 loxP/loxP ::Gad2-iCreERT2, Oprm1 loxP/loxP:: vGlut1-iCreERT2, or Oprml ${ }^{\text {loxPloxP }}:: G F A P-C r e E R T 2$ mice and their control littermates (Oprm1-flox $+1+\because$ CreERT2-/-) were treated with tamoxifen (Sigma; dissolved in corn oil; 2 $\mathrm{mg} /$ day, i.p.) for 7 consecutive days to induce $\mu \mathrm{R}$-specific deletion. Two weeks after the last tamoxifen injection, the mice were used for experiments. The deletion of $\mu$ Rs in mutant mice was verified by an in situ hybridization assay. 


\section{Surgery and intra-hippocampal injection}

Mice were anaesthetized with $0.8-1.5 \%$ isoflurane from a vaporizer (Fluotec-Ohmeda, Tewksbury, MA, USA) and fixed on a stereotaxic apparatus (SR-5; Narishige, Tokyo, Japan). Guide cannulas (23 gauge with stylets) made of stainless steel tubing were implanted into the bilateral dorsal hippocampus (anteroposterior, $-1.8 \mathrm{~mm}$ from bregma; mediolateral, $\pm 1.5 \mathrm{~mm}$ from bregma; dorsoventral, $-1.0 \mathrm{~mm}$ from brain surface). Mice were allowed 7 days of recovery before the behavioural experiments. Intra-hippocampal injection was performed by insertion of needles ( 30 gauge) through the cannulas. The injection needles were connected to $1-\mu \mathrm{l}$ syringes with polyethylene tubes and controlled by an automated microinjection pump (World Precision Instruments, Sarasota, FL, USA). Drug solutions were administered in a total volume of $1.0 \mu \mathrm{l} /$ mouse $(0.5 \mu \mathrm{l}$ on each side) at a rate of 0.1 $\mu \mathrm{l} / \mathrm{min}$. After injection, the needles were left in place for an additional 2 min to allow drug diffusion. At the end of the experiment, mice were sacrificed with a urethane overdose, and the brains were sliced to verify the cannula placements. The data were abandoned if the cannula tip was $>0.5 \mathrm{~mm}$ away from the correct placement. Naloxone, DAMGO, CTAP, naltrindole and nor-binaltorphimine were purchased from Tocris Bioscience, and bicuculline, L-655,708, and muscimol were purchased from Sigma. $\beta$-Endorphin antiserum (\#ab10339), enkephalin antiserum (\#ab77273) and control serum were provided by Abcam. All chemicals were dissolved in physiological saline unless otherwise stated.

\section{Elevated platform (EP) stress protocol}

Stress was applied to mice by placing them on an elevated circular Plexiglas platform ( $1.3 \mathrm{~m}$ high, $8 \mathrm{~cm}$ diameter) in a brightly lit room for $50 \mathrm{~min}$, whereas the control mice stayed in their home cages in the same room. Mice consistently urinated and/or defecated while on the platform. Immediately after stress was applied, mice were placed in a water maze for a memory-retrieval test or rapidly decapitated for either electrophysiological recording or collection of blood and brain tissue for corticosterone and Western blot analysis, respectively.

\section{Behavioural tests}

\section{Morris water maze (MWM) test}

The apparatus was a circular pool $(40 \mathrm{~cm}$ high and $100 \mathrm{~cm}$ diameter) filled with $21 \pm 1{ }^{\circ} \mathrm{C}$ water (depth of $20 \mathrm{~cm}$ ) that was made opaque with non-toxic white tempera paint powder. Visual landmarks with different colours and dimensions were placed near the pool for spatial orientation. The maze was divided into four imaginary quadrants. For hidden-platform training (on Day 1), a circular platform $(10 \mathrm{~cm}$ diameter) was hidden $1 \mathrm{~cm}$ below the water surface (invisible to the mice) in the centre of one quadrant (the target quadrant) and remained in that location throughout training. Mice received a single training session consisting of twelve consecutive trials with four different starting positions that were evenly distributed around the perimeter of the maze. If a mouse reached the platform within $60 \mathrm{~s}$, it was allowed to remain there for $20 \mathrm{~s}$ and was then placed in a holding cage for $5 \mathrm{~min}$ until the next trial. If a mouse searched for the platform for $>60 \mathrm{~s}$, it was guided to the platform gently by the experimenter. After completion of training, the animals returned to their home cages until probe testing $24 \mathrm{~h}$ later. The probe trial consisted of a 60 -s free-swim period with the platform removed. The mice were placed in the pool at a position equidistant from the target quadrant and the opposite quadrant. Swimming paths for all trials were monitored using a video camera system. The escape latency (latency to find the platform) during the training section and the time spent in the four different quadrants during the test trial were analysed using an EthoVision tracking system (Noldus, Leesburg, VA, USA). To compare memory retrieval among different groups, we calculated the ratio of the time spent in the target quadrant to the value that would be expected by chance $(15 \mathrm{~s})$.

\section{Open-field (OF) test}

To assess the possible effects of $\mu \mathrm{R}$ deletion on motor and emotional activities, we evaluated locomotor activity and emotional response in the OF test. Mice were gently placed individually in a corner of the OF box $(40 \times 40 \times 30 \mathrm{~cm})$, facing the opaque walls, and allowed to freely explore the box for $10 \mathrm{~min}$. The total distance travelled and the time spent in the centre area $(20 \times 20 \mathrm{~cm})$ were automatically recorded using a video camera system and analysed with EthoVision software (Version 1.9, Noldus Information Technology, USA).

\section{ELISA assays of Met/Leu-enkephalin and corticosterone}

Hippocampal Met/Leu-enkephalin concentrations and serum corticosterone levels were determined using the Mouse Enkephalin ELISA Kit (\#abx576248, Abbexa, Ltd., Cambridge Science Park, UK) and Corticosterone ELISA Kit (\#ADI-901-097, Enzo Life Sciences, Farmingdale, New York, USA) according to the manufacturer's instructions.

\section{Electrophysiological recordings}

Brain slices were prepared from mice that were anaesthetized with isoflurane and rapidly decapitated. The brains 
were chilled in oxygenated $4{ }^{\circ} \mathrm{C}$ modified artificial cerebrospinal fluid (ACSF), which contained the following (in $\mathrm{mM}$ ): 250 sucrose, $2.5 \mathrm{KCl}, 1.2 \mathrm{MgCl}_{2}, 1.2 \mathrm{NaH}_{2} \mathrm{PO}_{4}, 2.4$ $\mathrm{CaCl}_{2}, 26 \mathrm{NaHCO}_{3}$ and 11 glucose. Transverse slices (300 $\mu \mathrm{m})$ were cut with a vibratome (1000 plus; Vibratome Company, St. Louis, MO, USA). Slices were incubated in oxygenated standard ACSF for $1 \mathrm{~h}$ at room temperature $\left(23-25^{\circ} \mathrm{C}\right)$ to recover and then transferred to a recording chamber. The standard ACSF contained the following (in $\mathrm{mM}): 126 \mathrm{NaCl}, 2.5 \mathrm{KCl}, 1.25 \mathrm{NaH}_{2} \mathrm{PO}_{4}, 2 \mathrm{MgCl}_{2}, 2$ $\mathrm{CaCl}_{2}, 10$ glucose and $26 \mathrm{NaHCO}_{3}$, pH 7.4. CA1 pyramidal neurons were visualized with an upright microscope (DM LFSA, Leica, Germany). Whole-cell recordings were performed using a Multiclamp 700B amplifier (Molecular Devices, Sunnyvale, CA, USA). The recording pipettes had 3-5 $\mathrm{M} \Omega$ resistance when filled with the following solution (in $\mathrm{mM}$ ): $80 \mathrm{CsCH}_{3} \mathrm{SO}_{3}, 80 \mathrm{CsCl}, 10 \mathrm{HEPES}, 2 \mathrm{QX}-314,2$ $\mathrm{MgCl}_{2}, 0.2$ EGTA, 4 MgATP, $0.3 \mathrm{Na}_{2} \mathrm{GTP}, 10 \mathrm{Na}_{2}$-phosphocreatine ( $\mathrm{pH} 7.2$ with $\mathrm{CsOH}$ ).

Evoked excitatory postsynaptic currents (eEPSCs) and inhibitory postsynaptic currents (eIPSCs) were induced with a concentric bipolar electrode placed in the Schaffer collateral pathway, which was stimulated at $0.1 \mathrm{~Hz}$ (pulse of $100 \mu$ s duration). Input/output (I/O) curves were constructed by varying the stimulus intensity $(10-500 \mathrm{~mA})$ from a stimulation isolation unit controlled by a S88X stimulator (Grass Technologies, West Warwick, RI, USA) and measuring the peak eEPSC/eIPSC amplitude. eEPSCs were recorded in the presence of the $\mathrm{GABA}_{\mathrm{A}}$ receptor antagonist picrotoxin (PTX, $100 \mu \mathrm{M}$, Sigma). eIPSCs were recorded in the presence of the glutamate receptor antagonists D-AP5 (50 $\mu \mathrm{M}$, Sigma) and DNQX (20 $\mu \mathrm{M}$, Sigma). The eEPSC and eIPSC responses were verified by bath application of PTX $(100 \mu \mathrm{M})$ and DNQX $(20 \mu \mathrm{M})$, respectively. Individual data were normalized to the respective maximal response. For analysis of paired-pulse facilitation/depression of eIPSC amplitude, the neuron was voltage clamped at $-70 \mathrm{mV}$, and pairs of stimuli were applied at varying interpulse intervals (50, 100, and $200 \mathrm{~ms})$. The paired-pulse ratio (PPR) was calculated by determining the ratio of the peak amplitude values of evoked eIPSC2/eIPSC 1 by pairedpulse stimulation at each interpulse interval. To obtain eEPSC/eIPSC (E/I) ratios under standard ACSF bath conditions, we used the average of the maximal peak from 10 eEPSCs (voltage clamped at $-70 \mathrm{mV}$ ) and the average of the maximal peak of 10 eIPSCs (voltage clamped at $0 \mathrm{mV}$ ). Spontaneous inhibitory postsynaptic currents (sIPSCs) and miniature inhibitory postsynaptic currents (mIPSCs) were recorded at a holding potential of $-70 \mathrm{mV}$ with $50 \mu \mathrm{M}$ D-AP5 and $20 \mu \mathrm{M}$ DNQX in standard ACSF. For mIPSC recordings, $1 \mu \mathrm{M}$ tetrodotoxin (Fishery Science and Technology Development Co., China) was added. sIPSCs and mIPSCs were analysed starting 4-10 min from the beginning of whole-cell recording. Before the tonic inhibitory current was measured, the baseline current was stabilized with $50 \mu \mathrm{M}$ D-AP5 and $20 \mu \mathrm{M}$ DNQX to block AMPA and NMDA-receptor-dependent postsynaptic currents. The amplitude of the tonic GABA current was measured by the baseline shift after $100 \mu \mathrm{M}$ bicuculline administration. Tonic current density was calculated from the current amplitude divided by the membrane capacitance.

\section{Western blotting analysis}

Hippocampal slice surface proteins were labelled with EZLink Sulfo-NHS-SS-Biotin as described previously [25]. Briefly, after recovery, slices were incubated with ACSF containing $1 \mathrm{mg} / \mathrm{ml}$ EZ-Link Sulfo-NHS-SS-Biotin (\#21331, Pierce Chemical Co., Rockford, IL, USA) for $45 \mathrm{~min}$. Then, the slices were rinsed 3 times with oxygenated ACSF containing glycine, homogenized in $500 \mu \mathrm{l}$ of modified radioimmunoprecipitation assay buffer $(50 \mathrm{mM}$ Tris-HCl, $\mathrm{pH} 8 ; 150 \mathrm{mM} \mathrm{NaCl} ; 1 \%$ Triton X-100 and $1 \%$ sodium deoxycholate; $10 \mu \mathrm{g} / \mathrm{ml}$ leupeptin; $100 \mu \mathrm{g} / \mathrm{ml}$ TPCK; and $1 \mathrm{mM}$ PMSF), and then centrifuged at $14,000 \times \mathrm{g}$ for $15 \mathrm{~min}$. Proteins (150-300 $\mu \mathrm{g}$ ) were incubated overnight in an end-over-end shaker in the presence of Streptavidin beads (\#20349, Pierce Chemical Co., Rockford, IL, USA). The entire process was carried out at $4{ }^{\circ} \mathrm{C}$. The Beads were thoroughly washed, resuspended in $30 \mu \mathrm{l}$ loading buffer, and analysed by Western blots as described below.

Protein concentrations were determined by the Lowry method. Protein samples were separated by $10 \%$ SDSPAGE and transferred to a nitrocellulose membrane. After being blocked at room temperature in $10 \%$ milk in TBST buffer $(10 \mathrm{mM}$ Tris- $\mathrm{HCl}, 120 \mathrm{mM} \mathrm{NaCl}$, and $0.1 \%$ TWEEN 20, $\mathrm{pH} 7.4$ ) for $1 \mathrm{~h}$, the membrane was probed with antibodies against $\mu \mathrm{R}$ (1:500; \#ab10275, Abcam, USA), phospho- $\mu \mathrm{R}$ (Ser375, 1:1 000; \#bs-3724R, BIOSS, USA) and $\beta$-actin ( $1: 1 \quad 000$; \#4970, Cell Signalling Technology, USA) at $4{ }^{\circ} \mathrm{C}$ overnight. The membranes were then washed three times in TBST, followed by incubation with $1: 10,000$ dilutions of horseradish peroxidase-conjugated anti-rabbit/mouse $\operatorname{IgG}$ at room temperature for $1 \mathrm{~h}$ and washed three times in TBST. Visualization was carried out using a chemiluminescence kit (Bio-Rad). The density of the bands was quantified by densitometric analysis of the scanned blots using Bio-Rad software. Rat $\mu \mathrm{R}$ peptide (\#ab46988, Abcam, USA) was used to verify the specificity of the $\mu R$ antibody (\#ab10275, Abcam, USA) by Western blot. After being blocked with $10 \%$ milk in TBST, the membrane was incubated with primary antibody or mixture (antibody mixed with peptide; antibody:peptide $=1: 2$ ) overnight at $4{ }^{\circ} \mathrm{C}$. 


\section{Fluorescence in situ hybridization with RNAscope}

The deletion of $\mu$ Rs in mutant mice was verified by fluorescent in situ hybridization assay. Briefly, mice were deeply anaesthetized with isoflurane and sacrificed by perfusion with $4{ }^{\circ} \mathrm{C}$ saline $(0.9 \%, \mathrm{pH} 7)$ within $5 \mathrm{~min}$. The brains were quickly removed from the skulls and frozen on dry ice and then embedded in OCT (\#Tissue-Tek 4583, Sakura Finetek USA Inc., Torrance, CA). Fresh frozen sections $(16 \mu \mathrm{m})$ were made coronally through the hippocampal formation with a freezing microtome (CM1950, Leica Microsciences, Germany) and thaw mounted onto Superfrost Plus Microscope Slides (\#12-550-15, Fisher Scientific, Pittsburgh, PA, USA). The sections were fixed in $4 \%$ PFA for $60 \mathrm{~min}$ at $4{ }^{\circ} \mathrm{C}$ before being dehydrated using graded ethanol (50, 70, 100 and $100 \%$ ) at room temperature for $5 \mathrm{~min}$ each and finally air dried. The sections were incubated with $\mathrm{H}_{2} \mathrm{O}_{2}$ for $10 \mathrm{~min}$ and subsequently pretreated with protease IV for $15 \mathrm{~min}$. The probes for Oprml (sixteen synthetic oligonucleotides complementary to the nucleotide sequence 590-1458 of Oprm1), Gad2 (\#39371), vGlut1 (\#416631) and GFAP (\#313211) were provided by Advanced Cell Diagnostics (ACD, USA) and conjugated to Atto 550 and Atto 647, respectively. The procedure for in situ detection was performed using RNAscope Multiplex Fluorescent Reagent Kit v2 (\#323100, ACD) according to the manufacturer's instructions for fresh frozen tissue. After being heated with a HybEZTM oven (ACD, USA) for $2 \mathrm{~h}$, slides were mounted with the ProLong Gold Antifade Mountant (\#P10144, Thermo Fisher Scientific, Pittsburgh, PA, USA). Confocal images were captured with a laser scanning microscope (Leica, TCS SP5, Germany), and cells with positive labelling were counted.

\section{Statistical analysis}

Data were presented as the mean \pm standard error of the mean (SEM), or sometimes as the mean \pm SEM \%, and analysed (not in a blinded manner) using SPSS 20. Normality was tested with the Shapiro-Wilk test, and equal variance was evaluated before ANOVA. Statistical analysis of the data was performed using Student's $t$-test (two-tailed), the Kolmogorov-Smirnov (K-S) test, one-way analysis of variance (ANOVA) or repeated-measures (RM) ANOVA, as stated individually in the results section. The ANOVAs were followed by post hoc tests (Fisher's test). Statistical significance was set at $p<0.05$.

\section{Results}

During the 12 trials of training in the MWM task, the escape latencies of all naïve mice $(n=41)$ progressively decreased, showing successful spatial memory acquisition (Supplementary Figure 1a). Twenty-four hours later, the trained mice were randomly divided into the unstressed $(n=21)$ and stressed groups $(n=20)$. Both groups were subjected to the probe test, with the stressed group undergoing $50 \mathrm{~min}$ of EP stress immediately prior to the probe test. Although no difference in motor capacity, shown as average swimming speed, was observed between the two groups (Supplementary Figure 1b), the unstressed mice performed well and spent significantly longer in the target quadrant than in the opposite quadrant $(23.33 \pm 1.58 \mathrm{~s}$ vs. $7.01 \pm 0.78 \mathrm{~s})$, whereas the stressed mice spent similar amounts of time in each of those two quadrants, spending significantly less time in the target quadrant than the unstressed mice (Supplementary Figure 1c). These results demonstrate that acute EP stress before the probe test significantly impairs the retrieval of spatial reference memory. In addition, such impairment effects of EP stress on memory retrieval lasted for at least $2 \mathrm{~h}$ (Supplementary Figure 1d).

\section{Hippocampal $\mu R s$ are necessary for stress-induced impairment of memory retrieval}

The nonspecific opioid receptor antagonist naloxone was first used (3 mg/kg, i.p.) to address the involvement of EOPs in the stress-induced impairment of memory retrieval. Intraperitoneal injection (i.p.) of naloxone $(3 \mathrm{mg} / \mathrm{kg}$ ) or its vehicle had no significant effect on the memory retrieval of unstressed mice (Fig. 1a), but naloxone injection $30 \mathrm{~min}$ before EP stress completely abolished the memory-retrieval impairment observed in the stressed mice (Fig. 1a), suggesting that the opioid receptors are required for this memory impairment. No significant difference was detected in swimming speed among the treated groups (Supplementary Figure 2a).

Three major opioid receptors, the $\mu R s, \delta$-opioid receptors $(\delta \mathrm{Rs})$, and $\kappa$-opioid receptors ( $\kappa \mathrm{Rs})$, are expressed in the hippocampus. In order to specify the subtype of opioid receptors involved in the responses to EP stress, selective opioid receptor antagonists were then bilaterally microinjected into the hippocampal CA1 region $15 \mathrm{~min}$ before EP stress. Intra-hippocampal infusion of the $\mu \mathrm{R}$ antagonist $\mathrm{CTAP}$, the $\delta \mathrm{R}$ antagonist naltrindole or the $\mathrm{KR}$ antagonist nor-binaltorphimine $65 \mathrm{~min}$ before the probe test did not affect the memory retrieval (Fig. 1b) of the unstressed mice ( $p>0.05$, compared with the saline group of unstressed mice). The application of CTAP $(0.5 \mu \mathrm{g} / \mu \mathrm{l})$, but not any dose of naltrindole $(2.26 \mu \mathrm{g} / \mu \mathrm{l}$ or $4.52 \mu \mathrm{g} / \mu \mathrm{l})$ or norbinaltorphimine $(3.85 \mu \mathrm{g} / \mu \mathrm{l}$ or $7.70 \mu \mathrm{g} / \mu \mathrm{l})$, completely eliminated the stress-induced impairment of memory retrieval (Fig. 1b; Supplementary Figure 1e). The stressed mice in the CTAP group spent significantly more time in the target quadrant than the stressed mice in the saline, 


\section{a}

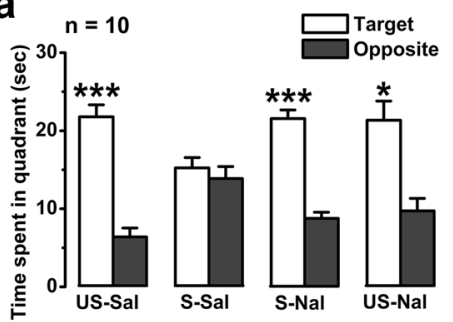

b

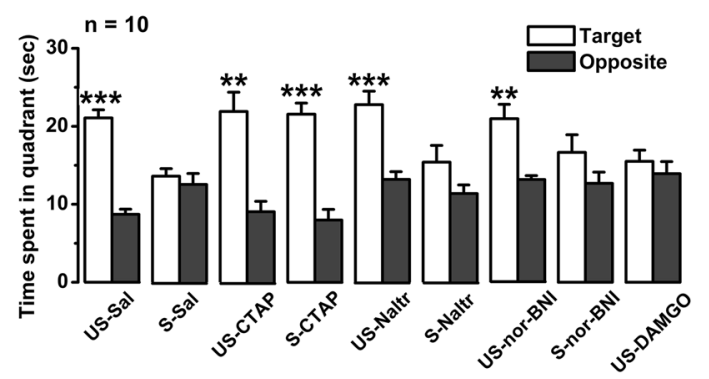

C

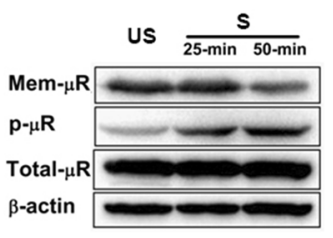

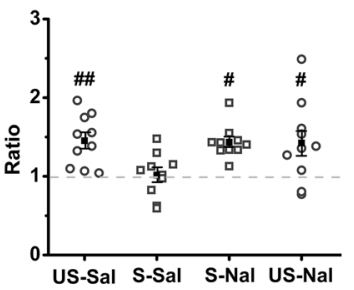
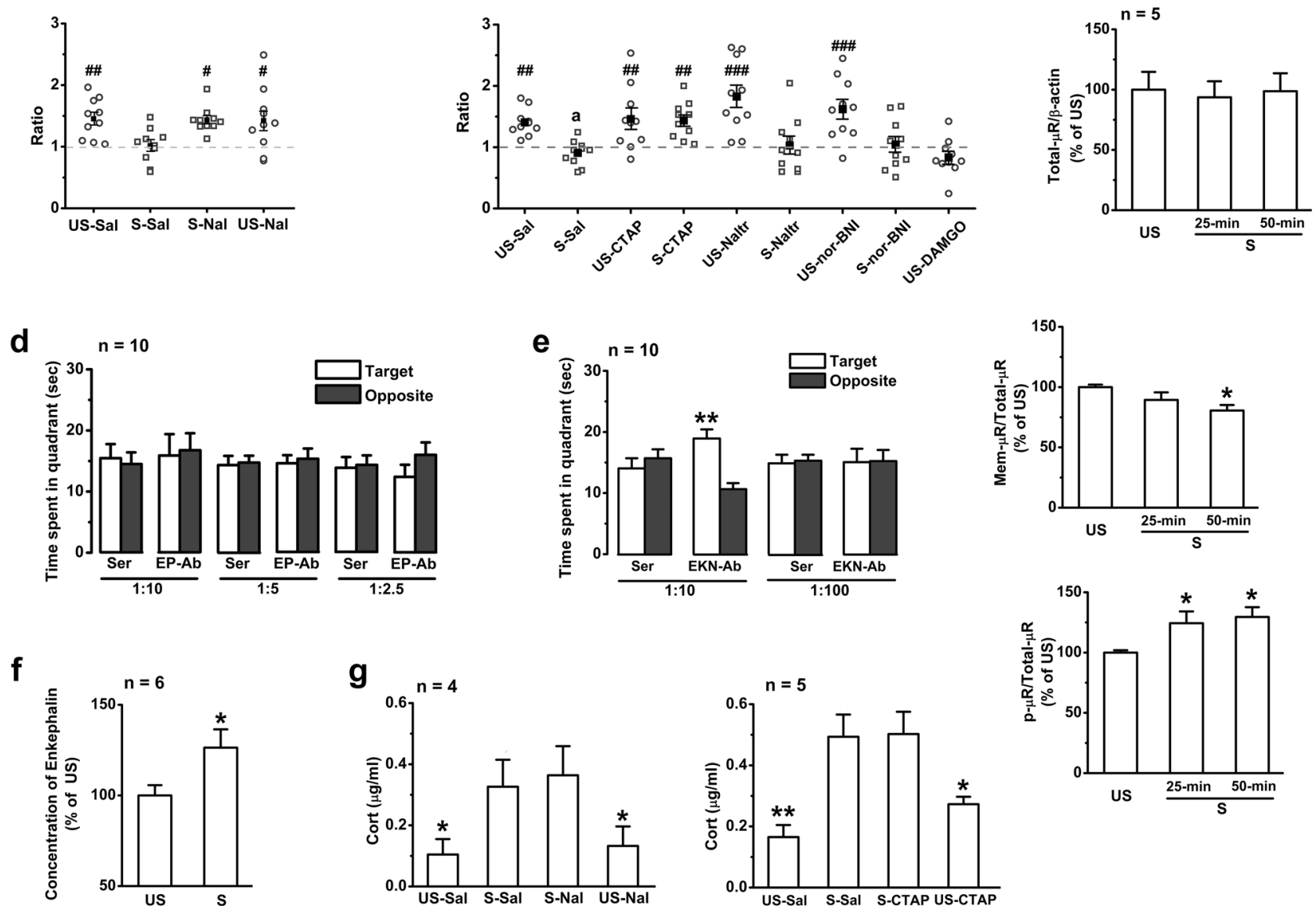

Fig. 1 EP stress impairs memory retrieval in the MWM task by activating hippocampal $\mu$ Rs. a The effects of systemic injection of naloxone or saline on time spent in the target/opposite quadrants and the target time ratio during probe test of the stressed and unstressed mice. *, target vs. opposite within-group, paired Student's $t$-test. The target time ratio $F_{3,36}=3.59, p=0.023$, one-way ANOVA; \#, vs. $\mathrm{S}$-Sal. b The effects of bilateral intra-hippocampal infusion of CTAP $(0.5 \mu \mathrm{g} / \mu \mathrm{l})$, naltrindole $(2.26 \mu \mathrm{g} / \mu \mathrm{l})$, nor-binaltorphimine $(3.85 \mu \mathrm{g} / \mu \mathrm{l})$, DAMGO $(0.5 \mu \mathrm{g} / \mu \mathrm{l})$, or saline on memory retrieval. The target time ratio $F_{8,81}=7.00, p=0.000$, one-way ANOVA; \#, vs. S-Sal. c The effects of EP stress on the levels of hippocampal $\mu \mathrm{R}$ proteins and their phosphorylation. Total $\mu \mathrm{Rs} F_{2,15}=0.25, p=0.784$; cell surface $\mu \mathrm{Rs}$ $F_{2,12}=4.09, p=0.044$; phosphorylated $\mu$ Rs $F_{2,12}=4.75, p=0.030$; one-way ANOVA; *, vs. unstressed. d Hippocampal injection of

naltrindole, or nor-binaltorphimine group $(21.54 \pm 1.42 \mathrm{~s}$ vs. $13.59 \pm 0.97, \quad 15.40 \pm 2.15, \quad 16.65 \pm 2.25 \mathrm{~s}$, respectively) Furthermore, microinjection of DAMGO $(0.5 \mu \mathrm{g} / \mu \mathrm{l})$, a selective $\mu \mathrm{R}$ agonist, in the CA1 regions of the unstressed
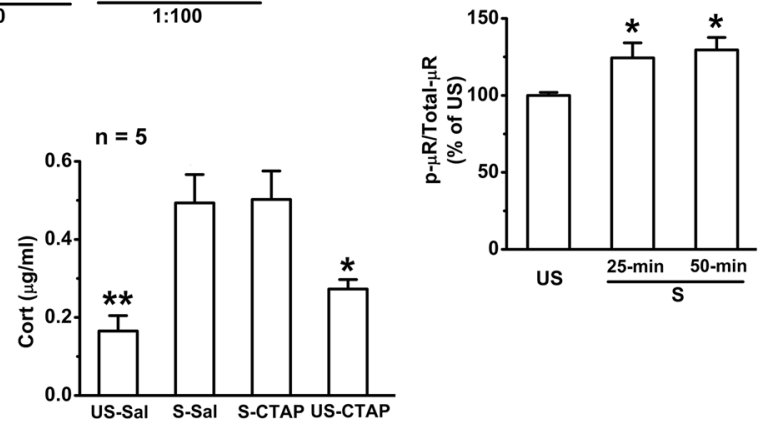

$\beta$-endorphin antiserum does not affect stress-induced memory impairment. e Hippocampal injection of enkephalin antiserum at a concentration of $1: 10$ before stress abolishes memory impairment. f The level of Met/Leu-enkephalin in hippocampal tissues. g The effects of systemic application of naloxone or bilateral intrahippocampal infusion with CTAP on the level of serum corticosterone immediately after 50-min stress. $F_{3,12}=4.22, p=0.030$ for naloxone groups, and $F_{3,12}=8.74, p=0.000$ for CTAP groups, oneway ANOVA; *, vs. stress. One symbol, $p<0.05$; two symbols, $p<$ 0.01 ; three symbols, $p<0.001$. US un-stress, $S$ stress, Sal saline, Nal naloxone, Naltr naltrindole, nor-BNI nor-binaltorphimine, Cort corticosterone, Mem- $\mu R$ cell surface $\mu \mathrm{Rs}, p-\mu R$ phosphorylated $\mu \mathrm{Rs}$, $E K N-A b$ enkephalin antiserum, $E P-A b \beta$-endorphin antiserum, $S e r$ control serum

mice prior to the probe test reproduced memory-retrieval impairment similar to that observed in the stressed mice (Fig. 1b). Given that the acquisition was not affected by cannula implantation (Supplementary Figure 1a) and that 
swimming speed in the probe test was not affected by the administration of any of the drugs (Supplementary Figure $2 b$ ), it is reasonable to conclude that the EP-stressinduced impairment of memory retrieval specifically requires activation of $\mu \mathrm{Rs}$ in the hippocampus.

Upon EOP binding on $\mu R$ s, phosphorylation of the serine at position 375 (Ser375) on the C-terminal tail of $\mu \mathrm{Rs}$ occurs and further promotes receptor internalization and trafficking [26]. We probed the levels of $\mu$ Rs and phospho$\mu R s$ (at Ser375 site) with the specific antibodies (Supplementary Figure 3). Consistent with the previous results obtained using an agonist [26], the levels of Ser375 phosphorylation in the hippocampus increased significantly after 25 or 50-min EP stress (Fig. 1c). Although the total amount of $\mu \mathrm{R}$ protein remained unchanged, the level of cell-surface $\mu$ Rs was significantly reduced $50 \mathrm{~min}$ but not $25 \mathrm{~min}$ after EP stress (Fig. 1c), suggesting that endocytosis of membrane $\mu \mathrm{Rs}$ occurred following phosphorylation. These results consistently indicate the binding of EOPs with $\mu$ Rs in the hippocampus during EP stress.

The hippocampus is enriched with endorphinergic projections and enkephalinergic neurons that can release $\beta$-endorphin and Met/Leu-enkephalin, respectively, which have high binding affinity for $\mu$ Rs [27]. To test whether $\mu R$ is endogenously activated by EOPs during stress and therefore impairs memory retrieval, we inhibited the function of $\beta$-endorphin and Met/Leu-enkephalin with their respective antiserums [28, 29]. Bilateral hippocampal microinjection with the $\beta$-endorphin antiserum at different dilutions (1:10, 1:5 and 1:2.5) 65 min before EP stress did not affect the impairment of memory retrieval (Fig. 1d), whereas microinjection of the Met/Leu-enkephalin antiserum at a concentration of 1:10 completely abolished the memory-retrieval impairment induced by EP stress (Fig. 1e). Furthermore, a significant increase in Met/Leuenkephalin in hippocampal tissues was detected immediately after the stress (Fig. 1f). Microinjection of Met/Leuenkephalin antiserum at 1:100 or its control serum did not show such an abolishing effect (Fig. 1e). Swimming speed in all treated groups (Supplementary Figures 4a-b) and memory retrieval in the unstressed groups (Supplementary Figure 4c) were not affected by antiserum or control serum injection. These results demonstrate that activation of $\mu \mathrm{Rs}$ by endogenous enkephalin plays an important role in the memory-retrieval impairment induced by EP stress.

Given the critical role of corticosteroid hormones in stress-induced memory impairments [3, 7], it is possible that the $\mu \mathrm{R}$ inhibitors might reverse memory-retrieval impairment via inhibiting corticosterone release on CA1 glutamatergic synapses. To our surprise, neither systemic application of naloxone nor intra-hippocampal infusion of CTAP (Fig. 1g) affected the elevation of corticosterone levels caused by EP stress.

\section{Stress-induced impairment of memory retrieval depends on activation of $\mu \mathrm{Rs}$ on GABAergic neurons}

In the central nervous system, $\mu$ Rs are widely expressed in different cell types, including GABAergic inhibitory interneurons [16], astrocytes [30], and even glutamatergic neurons [31]. To further determine the functional site of EOPs in stress-induced impairment of memory retrieval, Oprml flox (Supplementary Figure 5) mice were constructed to conditionally delete the Oprml gene in different cell types. We developed four mouse lines lacking $\mu \mathrm{Rs}$ in all tissues (referred to as $\mu \mathrm{R}-/-$ ), GABAergic inhibitory interneurons $\left(\mu \mathrm{R}_{\mathrm{GABA}}-/-\right)$, glutamatergic neurons $\left(\mu \mathrm{R}_{\mathrm{Glut}}-/-\right)$, and astroglial cells $\left(\mu \mathrm{R}_{\mathrm{Astro}}-/-\right)$ (see 'Methods and materials'). The fluorescent in situ hybridization studies confirmed the absence of $\mu$ Rs non-selectively in all tissues (Supplementary Figure 6) or selectively in GAD2-positive neurons, vGLUT1positive neurons, and GFAP-positive cells (Supplementary Figure 7), respectively, in the CA1 region, suggesting the validity of $\mu \mathrm{R}$ deletions. In each of the knockout lines and their littermate control $\left(\mu \mathrm{R}+/+, \mu \mathrm{R}_{\mathrm{GABA}}+/+, \mu \mathrm{R}_{\mathrm{Glut}}+/+\right.$, and $\mu \mathrm{R}_{\text {Astro }}+/+$ ), no significant difference was observed in the memory acquisition (Supplementary Figures 8a-d) and retrieval of the MWM test (Figs. 2a-d), locomotion distance and time spent in the centre zone of the OF test (Supplementary Figures 8a-d), indicating that non-selective or celltype-selective deletion of $\mu$ Rs does not affect learning and memory, emotion, or locomotor behaviour. In addition, no significant difference was found in swimming speed between any line of knockout mice and their littermate controls regardless whether they were stressed (Supplementary Figures 8a-d). Similar to the effects of naloxone systemic treatment (Fig. 1a), non-selective $\mu \mathrm{R}$ deletion prevented the stress-induced impairment of spatial memory retrieval (Fig. 2a). Furthermore, selective $\mu \mathrm{R}$ deletion from GABAergic neurons abolished the stress-induced impairment of memory retrieval, which remained in the $\mu \mathrm{R}_{\mathrm{GABA}}+/+$ mice (Fig. 2b). On the other hand, selective $\mu \mathrm{R}$ deletion in glutamatergic neurons or in astroglial cells had no impact on the stress-induced memory impairment (Figs. 2c, d). Together with the results of hippocampal microinjection with $\mu \mathrm{R}$ antagonists and agonists, these results definitively reveal the essential role of $\mu$ Rs on GABAergic neurons in stressinduced memory impairment.

\section{EP stress depresses GABAergic synaptic transmission onto CA1 pyramidal neurons in a $\mu R_{G A B A}$-dependent manner}

The eEPSCs and eIPSCs of pyramidal neurons were recorded in vitro to investigate the changes in basal excitatory and inhibitory synaptic transmission, respectively, in CA1 slices that were prepared immediately after EP stress. 


\section{a}

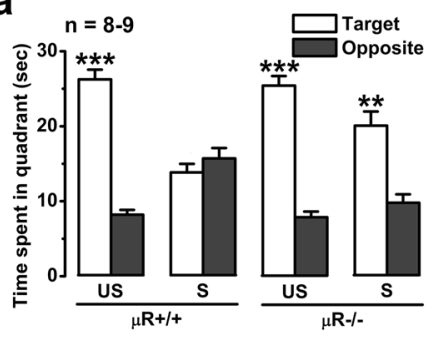

C

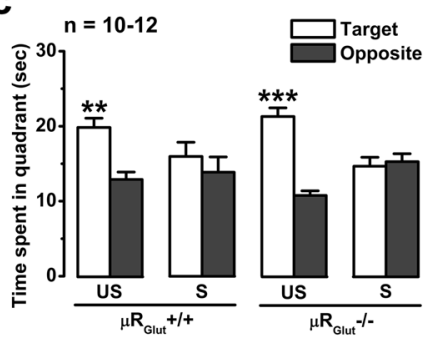

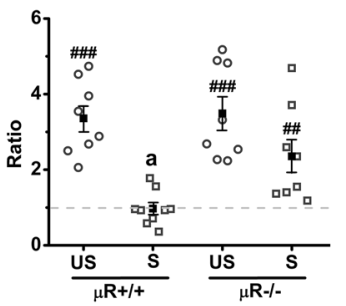

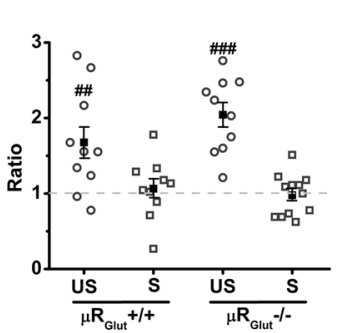

b

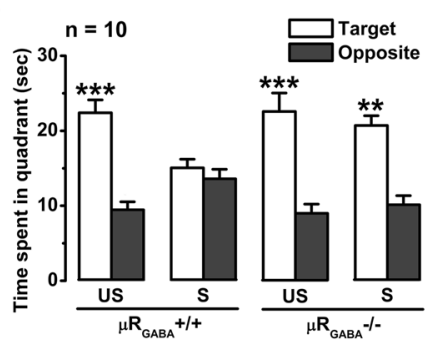

d

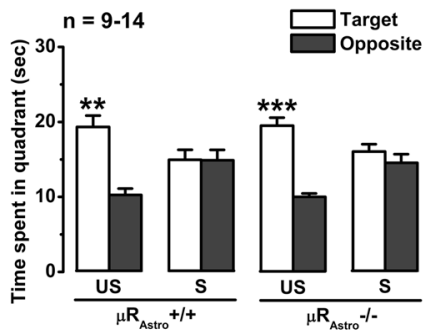

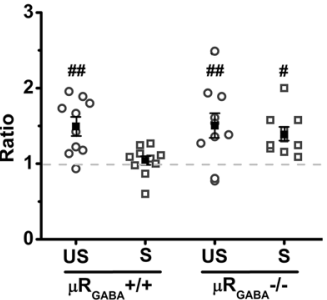

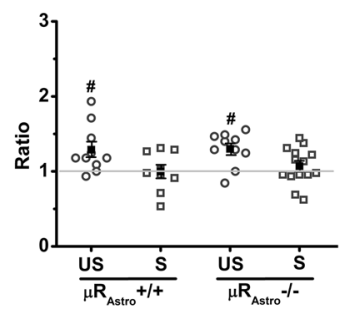

Fig. $2 \mu \mathrm{R}_{\mathrm{GABA}}$ but not $\mu \mathrm{R}_{\mathrm{Glut}}$ or $\mu \mathrm{R}_{\mathrm{Astro}}$ deletion prevents the $\mathrm{EP}$ stressinduced impairment of spatial memory retrieval. a-d The effects of stress on memory retrieval of $\mu \mathrm{R}-I-(\mathbf{a}), \mu \mathrm{R}_{\mathrm{GABA}}-I-(\mathbf{b}), \mu \mathrm{R}_{\mathrm{Glut}}-/-(\mathbf{c})$, and $\mu \mathrm{R}_{\text {Astro }}-/-$ mice (d). *, target vs. opposite within-group, paired Student's $t$-test. The target time ratio $F_{3,29}=10.95, p=0.000$ for

$\mu \mathrm{R}-1-; F_{3,36}=3.76, p=0.019$ for $\mu \mathrm{R}_{\mathrm{GABA}}-/-$ mice; $F_{3,38}=11.86$, $p=0.000$ for $\mu \mathrm{R}_{\mathrm{Glut}}-/-$; and $F_{3,39}=3.44, p=0.026$ for $\mu \mathrm{R}_{\mathrm{Astro}}-/-$; one-way ANOVA. \#, vs. the stressed $\mu \mathrm{R}+/+, \mu \mathrm{R}_{\mathrm{GABA}}+/+, \mu \mathrm{R}_{\mathrm{Glut}}+/+$, or $\mu \mathrm{R}_{\mathrm{Glut}}+/+$, respectively. One symbol, $p<0.05$; two symbols, $p<$ 0.01 ; three symbols, $p<0.001$. US unstressed, $S$ stressed

The I/O curve of eIPSCs (Fig. 3b), but not of eEPSCs (Fig. 3a), shifted rightward significantly in the stressed mice compared with the unstressed mice. The PPR of eIPSCs in slices from the stressed mice was markedly larger than that from the unstressed mice (Fig. 3c), implying a presynaptic depression on the basal inhibitory transmission by EP stress. To evaluate the E/I ratio, we recorded eEPSCs (voltage clamped at $-70 \mathrm{mV}$ ) and eIPSCs (voltage clamped at $0 \mathrm{mV}$ ) from identical CA1 pyramidal neurons. The results from the stressed mice exhibited a profound increase in the E/I ratio (Fig. 3d). These results suggest that EP stress leads to an $E / I$ imbalance by reducing the inhibitory inputs to CA1 pyramidal neurons.

Unlike the tonic currents mediated by extrasynaptic $\mathrm{GABA}_{\mathrm{A}}$ receptors, the phasic IPSCs evoked by spontaneous quantal release (including sIPSCs and mIPSCs) are mediated by intrasynaptic $\mathrm{GABA}_{\mathrm{A}}$ receptors [32]. The tonic inhibitory currents, revealed by bath application of bicuculline $(100 \mu \mathrm{M})$, showed no difference in CA1 pyramidal neurons between the stressed and unstressed mice (Fig. 3e). However, compared with the unstressed mice, the average frequency of sIPSCs in slices from the stressed mice was significantly depressed, and the cumulative distribution of their inter-event intervals (IEIs) was shifted rightward, while the average sIPSC amplitude remained unchanged (Fig. 3f). Similar changes were observed in the average frequency, average amplitude and cumulative distribution of IEIs in mIPSCs (Fig. 3g) of the stressed mice, together indicating that the neurotransmitter release from

GABAergic interneurons onto pyramidal neurons was markedly depressed following EP stress.

We next asked whether this depression of GABAergic transmission results from activation of $\mu$ Rs during stress. Administration of naloxone ( $3 \mathrm{mg} / \mathrm{kg}$, i.p.) did not alter the frequency and amplitude of sIPSCs (Fig. 3f) and mIPSCs (Fig. $3 \mathrm{~g})$ in the unstressed mice ( $p>0.05$, vs. saline mice). In contrast, naloxone injection prior to EP stress abolished the depression of the average frequencies of both sIPSCs (Fig. 3f) and mIPSCs (Fig. 3g), without significant influence on the average amplitudes. Moreover, bath application of specific $\mu \mathrm{R}$ agonist DAMGO $(1 \mu \mathrm{M})$ in slices from the unstressed mice for $30 \mathrm{~min}$ was capable of reproducing a significant depression in mIPSC frequency $(57.0 \%$ of baseline) similar to that observed in the stressed mice (55.8\% of unstressed level) (Fig. 4a). Interestingly, bath application of DAMGO in the same way was no longer able to further depress mIPSC frequency in slices from the stressed mice (Fig. 4b), indicating that the inhibiting effects of $\mu \mathrm{R}$ activation on GABAergic transmission might have been saturated by endogenous EOPs released during EP stress. The depression of GABAergic transmission by activation of $\mu$ Rs was indicated to occur presynaptically at the GABAergic terminals because application of DAMGO had no detectable effect on the amplitude of mIPSCs in slices from both the unstressed and stressed mice (Figs. 4a, b). These data thus provide strong evidence that activation of $\mu$ Rs is required for the EP stress-induced depression of GABAergic inhibitory transmission on CA1 pyramidal neurons. 

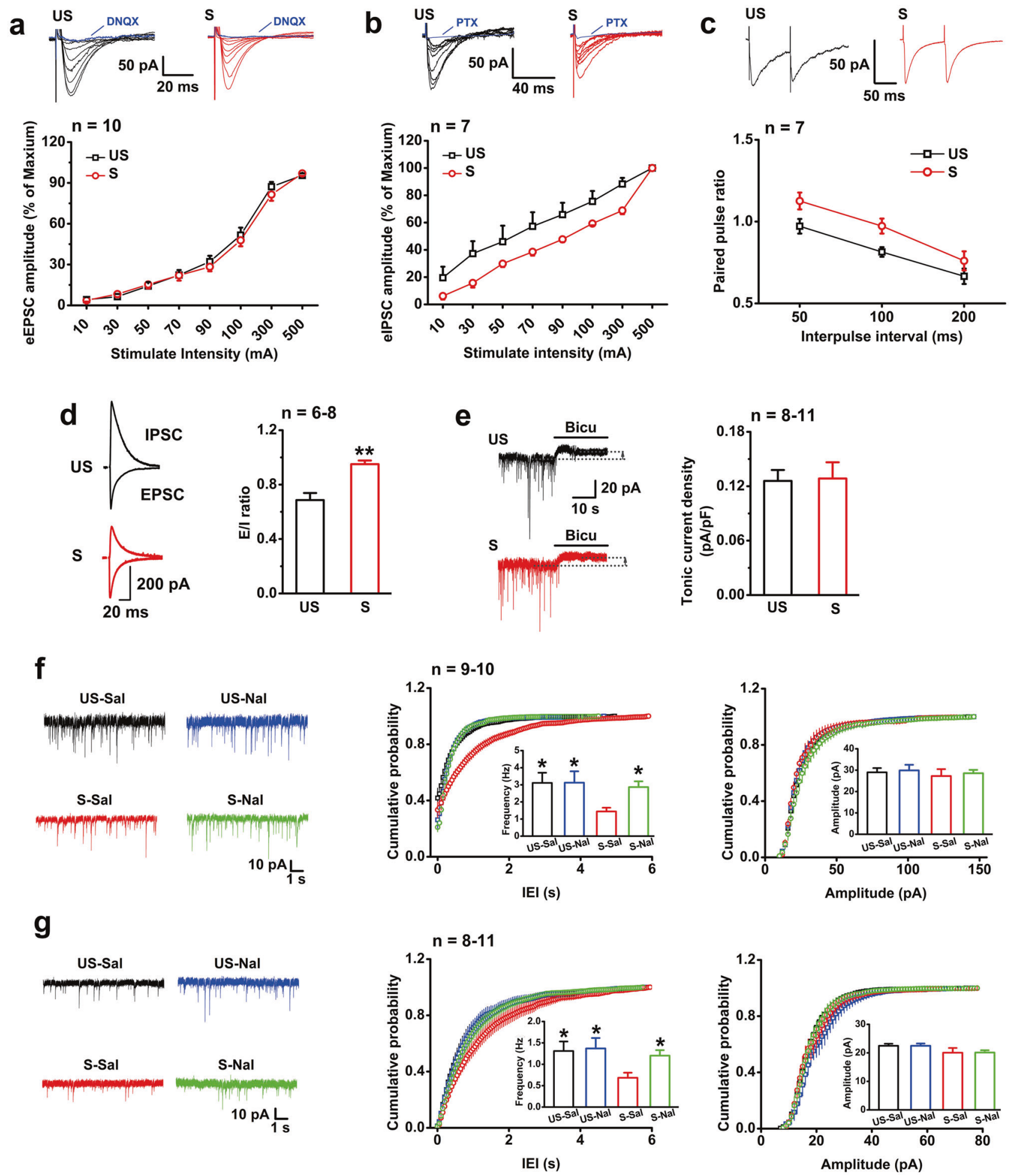

Given that the $\mu$ Rs on GABAergic neurons mediated stress-induced memory impairment (Fig. 2b), we then used $\mu \mathrm{R}_{\mathrm{GABA}}-1-$ mice to further verify the requirement of $\mu \mathrm{R}_{\mathrm{GABA}}$ in the observed depression of hippocampal GABAergic transmission and E/I imbalance. No significant difference in the E/I ratio (Fig. 4c), mIPSC frequency or amplitude (Fig. 4d) was observed between the unstressed $\mu \mathrm{R}_{\mathrm{GABA}}-/-$ and $\mu \mathrm{R}_{\mathrm{GABA}}+/+$ mice, showing that inducible $\mu \mathrm{R}_{\mathrm{GABA}}$ deletion did not affect basal synaptic release or $\mathrm{E} / \mathrm{I}$ balance. Bath application of DAMGO shifted the cumulative distribution of IEIs rightward and depressed mIPSC frequency only in slices from $\mu \mathrm{R}_{\mathrm{GABA}}+/+$ mice and not 
Fig. $3 \mathrm{EP}$ stress attenuates inhibitory synaptic transmission on CA1 pyramidal neurons. The number of cells labelled is equal to the number of animals used. a Stress does not alter the I/O curves of eEPSCs. The eEPSC was abolished by DNQX $(20 \mu \mathrm{M})$. Group $F_{1,17}=0.558, p=$ 0.465 ; groupxintensity $F_{9,153}=1.15, p=0.332$; RM ANOVA. b I/O curves of eIPSCs show a significant difference between the unstressed and stressed mice. The eIPSC was abolished by PTX $(100 \mu \mathrm{M})$. Group $F_{1,12}=4.94, p=0.046$; groupxintensity $F_{7,84}=$ $1.55, p=0.163$; RM ANOVA. c PPR of eIPSCs at different interpulse intervals. Group $F_{1,12}=9.78, p=0.009$; groupxinterval $F_{2,24}=0.34$, $p=0.717$; RM ANOVA. d The E/I ratio is increased in the stressed mice. e The tonic inhibitory currents of CA1 individual pyramidal neurons in slices from the unstressed and stressed mice are assessed by application of bicuculline. Stress does not affect the density of tonic inhibitory current. f EP stress depresses sIPSCs in CA1 pyramidal neurons, and this effect is reversed by naloxone administration. $p<$ 0.05 for cumulative probability of IEIs (S-Sal vs. US-Sal, US-Nal or S$\mathrm{Nal}$ ) and $p>0.05$ for cumulative probability of amplitude, K-S test. Mean values of frequency $F_{3,35}=4.46, p=0.021$; and mean values of amplitude $F_{3,35}=0.19, p=0.903$; one-way ANOVA; *, vs. S-Sal. g EP stress depresses mIPSCs in CA1 pyramidal neurons, and this effect is reversed by naloxone administration. $p<0.05$ for probability of IEIs (S-Sal vs. US-Sal, US-Nal or S-Nal) and $p>0.05$ for probability of amplitude, K-S test. Frequency $F_{3,33}=2.93, p=0.048$; amplitude $F_{2,26}=1.72, p=0.181$; one-way ANOVA; *, vs. S-Sal. One symbol, $p<0.05$; two symbols, $p<0.01$. US unstressed, $S$ stressed, Bicu bicuculline, Sal saline, Nal naloxone

slices from $\mu \mathrm{R}_{\mathrm{GABA}}-/-$ mice (Fig. $4 \mathrm{~d}$ ), indicating that the inhibitory function of $\mu$ Rs on GABAergic transmission is lacking in $\mu \mathrm{R}_{\mathrm{GABA}}-/-$ mice. As expected, stress-induced enhancement of the $E / I$ ratio in $\mu R_{\mathrm{GABA}}+/+$ mice was no longer present in $\mu \mathrm{R}_{\mathrm{GABA}}-/-$ mice (Fig. 4c). Consistently, the depression of mIPSC frequency induced by EP stress observed in $\mu \mathrm{R}_{\mathrm{GABA}}+/+$ mice was absent in $\mu \mathrm{R}_{\mathrm{GABA}^{-}} /$mice (Fig. 4d).

These electrophysiological results convincingly revealed that hippocampal GABAergic transmission on pyramidal neurons is depressed as a consequence of the specific activation of $\mu$ Rs on GABAergic neurons during EP stress.

\section{Depression of GABAergic inhibitory transmission in the hippocampus impairs memory retrieval}

The behavioural and electrophysiological results demonstrated that activation of $\mu \mathrm{R}_{\mathrm{GABA}}$ depresses hippocampal GABAergic transmission on pyramidal neurons and therefore impairs spatial memory retrieval. If the stress-induced impairment of memory retrieval indeed results from inhibition of GABAergic interneurons through activation of their $\mu \mathrm{Rs}$, it is reasonable to expect that diminishing GABAergic synaptic transmission by blocking $\mathrm{GABA}_{\mathrm{A}}$ receptors in the hippocampus will mimic the effects of stress on memory retrieval, whereas properly enhancing GABAergic transmission could counteract the effects of stress and attenuate the impairment. As shown in Fig. 5a, bilateral intra-hippocampal infusion of the $\mathrm{GABA}_{\mathrm{A}}$ receptor antagonist bicuculline (6.0 $\mathrm{ng} / \mu \mathrm{l}) 15 \mathrm{~min}$ before the probe test dramatically damaged memory retrieval in the unstressed mice to an extent similar to that observed in the stressed mice with saline infusion. It is well accepted that bicuculline non-selectively blocks $\mathrm{GABA}_{\mathrm{A}}$ receptor-mediated phasic/tonic currents and L655,708 selectively blocks the tonic inhibitory currents $[33,34]$. Unlike the impairment observed with bicuculline, intraperitoneal administration of L-655,708 $(0.7 \mathrm{mg} / \mathrm{kg})$ or its vehicle (DMSO) $45 \mathrm{~min}$ before the probe test did not affect memory retrieval in the unstressed mice (Fig. 5a). It is thus reasonably concluded that depression of phasic inhibitory currents is the mechanism underlying the memory-retrieval impairment induced by EP stress.

We then studied the effect of muscimol, a $\mathrm{GABA}_{\mathrm{A}}$ receptor agonist that can dose-dependently increase inhibitory currents $[35,36]$, on memory retrieval to further reinforce our theory. Because the over-activation of $\mathrm{GABA}_{\mathrm{A}}$ receptors by muscimol at high concentrations may inhibit the normal function of cortical pyramidal neurons and disrupt learning and memory by inactivating or perturbing the internal theta rhythmicity of the network [37, 38], we set up our experiments with various concentrations of muscimol. Bilateral intra-hippocampal infusion of muscimol at both $1.5 \mathrm{ng} / 1.0 \mu \mathrm{l}$ and $3.0 \mathrm{ng} / 1.0 \mu \mathrm{l} 15 \mathrm{~min}$ before the probe test did not significantly affect memory retrieval in the unstressed mice, whereas each of the following three large dosages of $6.0 \mathrm{ng} / 1.0 \mu \mathrm{l}, 12.0 \mathrm{ng} / 1.0 \mu \mathrm{l}$, and $24.0 \mathrm{ng} / 1.0 \mu \mathrm{l}$ damaged memory retrieval (Fig. $5 b$ ). When a sub-effective dose of muscimol $(1.5 \mathrm{ng} / 0.5 \mu \mathrm{l})$ was microinjected immediately after EP stress, memory retrieval remained unimpaired (Fig. 5c), suggesting that a small amount of muscimol is able to neutralize the stress-induced depression of GABAergic action by properly activating $\mathrm{GABA}_{\mathrm{A}}$ receptors on pyramidal neurons. Muscimol putatively potentiates both phasic and tonic inhibitory currents in CA1 pyramidal neurons. To rule out the possibility that muscimol neutralizes memory-retrieval impairment through the potentiation of tonic current, we administered saline or L-655,708 (i.p.) $30 \mathrm{~min}$ prior to muscimol infusion. As shown in Fig. 5d, in probe tests carried out 45 min after EP stress, both saline + DMSO and saline + L-655,708 groups still exhibited the memory retrieval impairment, whereas the combined muscimol + L-655,708 group showed no observable impairment. Given that the treatments did not affect swim speed (Supplementary Figures 2c-f), these data strongly suggest that depression of inhibitory transmission onto CA1 pyramidal neurons is crucial in the memoryretrieval impairment induced by EP stress.

\section{Discussion}

It has been well established that stress-induced impairments in learning and memory are associated with the direct effects 

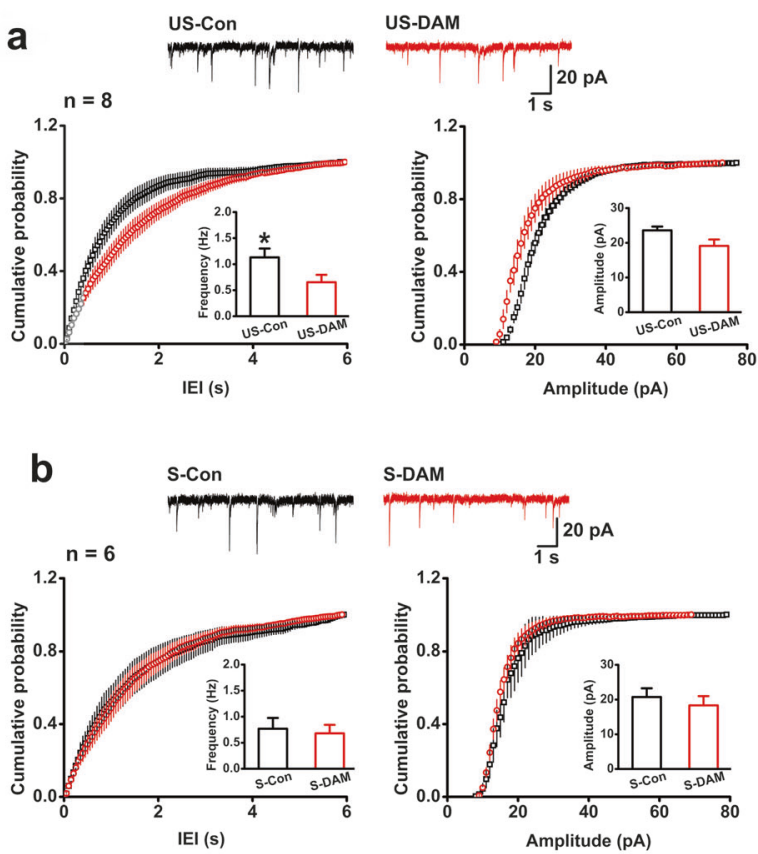

C
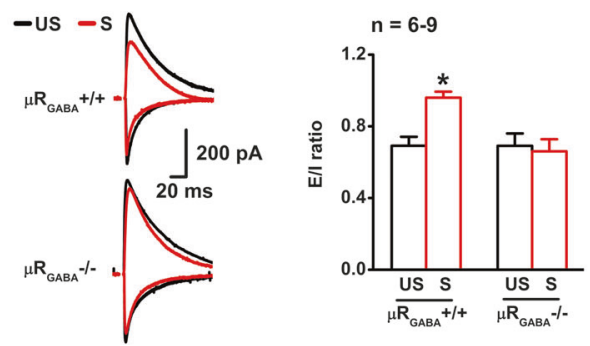

Fig. 4 EP stress occludes DAMGO perfusion-induced depression of mIPSC frequency. The number of cells labelled is equal to the number of animals used. a DAMGO perfusion significantly decreases mIPSC frequency but does not change mIPSC amplitude of the unstressed mice. $p<0.05$ for cumulative probability of IEIs, and $p>0.05$ for cumulative probability of amplitude, K-S test. $p=0.019$ for mean values of frequency and $p=0.098$ for mean values of amplitude, paired Student's $t$-test. b DAMGO perfusion does not influence the mIPSC frequency or amplitude of the stressed mice. $p>0.05$ for probability of IEIs and amplitude, K-S test. $p=0.742$ for mean values of frequency and $p=0.527$ for amplitude, paired Student's $t$-test. c

of glucocorticoid hormones on CA1 glutamatergic synaptic plasticity $[4-8,39]$. However, the present study revealed that in response to stress, EOPs are also responsible for the stressinduced impairment of memory retrieval through directly depressing CA1 GABAergic inhibitory interneurons. Furthermore, by using a combination of behavioural, biochemical, electrophysiological, and cell-type specific gene knockout techniques, the present paper provides several lines of coherent evidence, logically demonstrating that $\mu \mathrm{Rs}$ expressed at GABAergic inhibitory neurons are activated by EOPs and subsequently depress the GABAergic synaptic transmission onto pyramidal neurons in the setting of stressinduced impairment of memory retrieval.

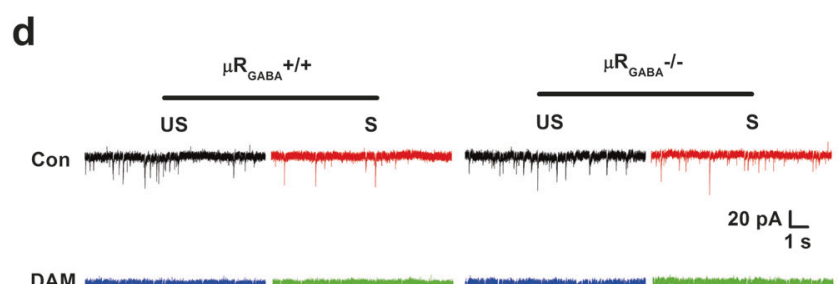

DAM
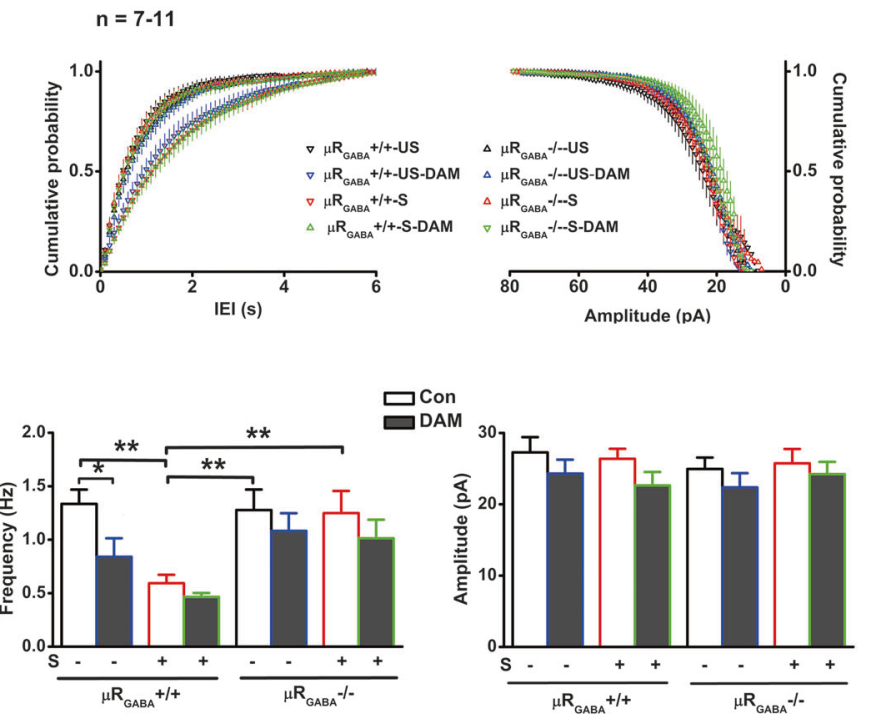

The stress-enhanced $\mathrm{E} / \mathrm{I}$ ratio is prevented by $\mu \mathrm{R}_{\mathrm{GABA}}$ deletion. $F_{3,26}=$ 4.73, $p=0.009$; one-way ANOVA. *, vs. unstressed $\mu \mathrm{R}_{\mathrm{GABA}}+/+$ or stressed $\mu \mathrm{R}_{\mathrm{GABA}}-/$-. d Deletion of $\mu \mathrm{R}_{\mathrm{GABA}}$ prevents the decrease in mIPSC frequency induced by EP stress or DAMGO perfusion. $p<$ 0.05 for cumulative probability of IEIs $\left(\mu \mathrm{R}_{\mathrm{GABA}}+/+-\mathrm{US}\right.$ vs. $\mu \mathrm{R}_{\mathrm{GABA}}$ $+/+-\mathrm{US}-\mathrm{DAM}, \mu \mathrm{R}_{\mathrm{GABA}}+/+-\mathrm{S}$, or $\left.\mu \mathrm{R}_{\mathrm{GABA}}+/+-\mathrm{S}-\mathrm{DAM}\right)$ and $p>$ 0.05 for cumulative probability of amplitude, K-S test. mIPSC frequency $F_{7,64}=4.37, p=0.000 ;$ mIPSC amplitude $F_{7,64}=0.85, p=$ 0.554 ; one-way ANOVA. One symbol, $p<0.05$; two symbols, $p<$ 0.01. US unstressed, $S$ stressed, Con control before DAMGO perfusion, DAM DAMGO

In response to stressful stimuli, activation of the autonomic nervous system (ANS) and the hypothalamicpituitary-adrenal (HPA) axis will trigger the release of a series of stress-related hormones and neuromodulators. It is believed that in coping with stress, released EOPs can promote adaptation and benefit the organism by preventing the development of stress-related mental or physical disorders $[10-12,40]$. In the hypothalamus, the corticotropinreleasing hormone $(\mathrm{CRH})$ and the arginine vasopressin (AVP)-containing neurons in the paraventricular nuclei $(\mathrm{PVN})$ are reciprocally connected with the proopiomelanocortin (POMC)-containing neurons in the arcuate nucleus. During stress, the CRH and AVP secreted from 

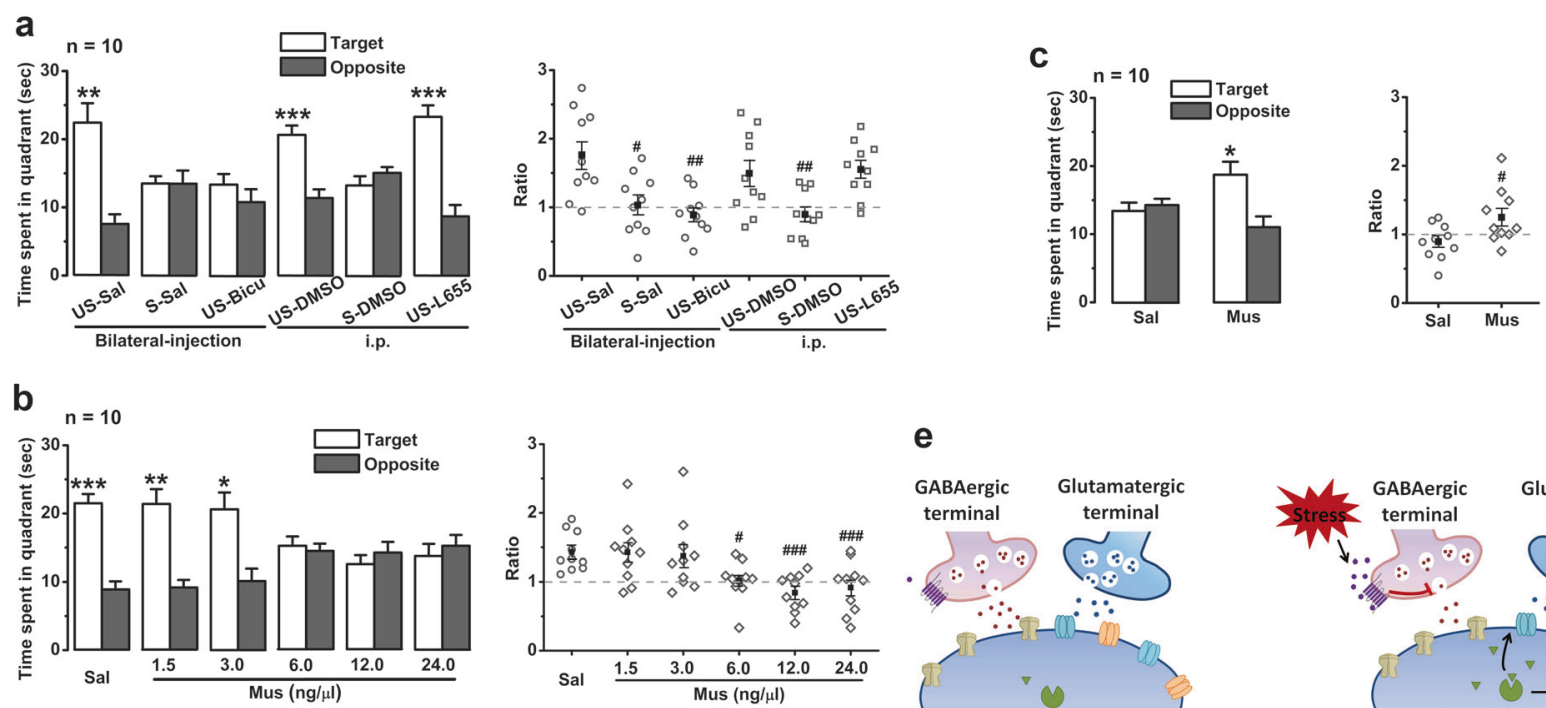

\section{e}
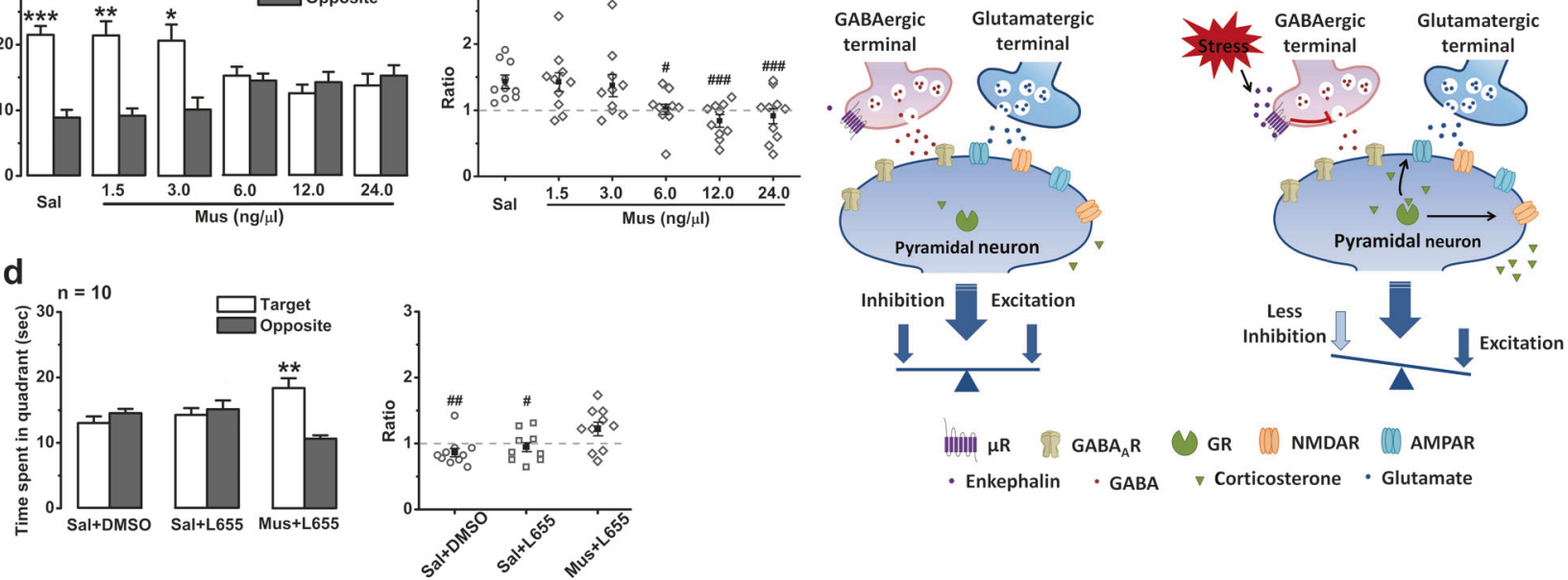

Fig. 5 Intrasynaptic $\mathrm{GABA}_{\mathrm{A}}$ receptor-mediated inhibitory currents modulate memory retrieval. Symbol *, target vs. opposite withingroup, paired Student's $t$-test. a Memory retrieval of unstressed mice is damaged by application of bicuculline but not L-655,708 or vehicle before probe test. The target time ratio $F_{5,54}=6.37, p=0.001$, oneway ANOVA; \#, vs. US-vehicle (saline or DMSO). b The effects of hippocampal infusion of different doses of muscimol on memory retrieval in unstressed mice. The target time ratio $F_{5,54}=6.34, p=$ 0.000, one-way ANOVA; \#, vs. Sal. (c) Muscimol $(1.5 \mathrm{ng} / 1.0 \mu \mathrm{l})$ infusion immediately after stress rescues the impaired memory retrieval. d Blocking tonic inhibitory currents with L-655,708 does not

PVN neurons can activate POMC-containing neurons to release $\beta$-endorphin and other POMC-derived EOPs to a number of brain regions, including the hippocampus $[11,41]$. It has been demonstrated that the hippocampal CA1 region contains an abundance of enkephalincontaining neurons and endorphinergic projections $[42,43]$. Stress can also enhance the release of Metenkephalin in the hippocampus $[11,44]$ to activate $\mu$ Rs or $\delta$ Rs [42]. Stress-induced release of EOPs can efficiently phosphorylate and internalize $\mu$ Rs, $\delta$ Rs or $\kappa R s$ with complicated mechanisms [45-48]. The present study shows that during acute stress, the enhanced hippocampal Met/Leuenkephalin specifically activates $\mu$ Rs to reduce local inhibitory transmission (Fig. 3 and Fig. 4) and then impairs retrieval of spatial memory in mice (Fig. 1b and Fig. 1e). Using $\mu \mathrm{R}-1-, \mu \mathrm{R}_{\mathrm{GABA}}-/-, \mu \mathrm{R}_{\mathrm{Glut}}-/-$ and $\mu \mathrm{R}_{\text {Astro }}-/-$ mice, we provide additional evidence demonstrating that it is the $\mu$ Rs expressed at GABAergic inhibitory neurons that

disturb the rescuing effect of muscimol on stress-impaired memory retrieval. The target time ratio $F_{2,27}=5.28, p=0.012$, one-way ANOVA; \#, vs. Mus + L655. One symbol, $p<0.05$; two symbols, $p<0.01$; three symbols, $p<0.001$. Sal saline, Bicu bicuculline, L655 L-655,708, Mus muscimol. e A schematic model for the two pathways in the hippocampus underlying the impairment of memory retrieval by acute stress. GR can directly modulate glutamatergic synaptic plasticity $[4,68]$ and affect memory retrieval. In addition, enkephalin triggered by acute stress in the hippocampus predominantly activates $\mu \mathrm{R}_{\mathrm{GABA}}$ and then disinhibits pyramidal neurons, resulting in E/I imbalance and impairment of memory retrieval

mediate stress-induced impairment of memory retrieval by depressing local inhibitory neurotransmission. Although it remains elusive how EP stress increases met-enkephalin release in the hippocampus, the present paper provides the first detailed evidence for the essential role of EOPs in local CA1 circuitry in acute stress-induced memory impairments.

It has been reported that exogenous activation of $\mu$ Rs by either systemic morphine injection [49] or intrahippocampal DAMGO microinjection (Fig. 1b) impaired memory retrieval in mice. However, the requirement of endogenous activation of $\mu$ Rs for normal spatial reference memory tasks was not observed using conventional $\mu \mathrm{R}$ knockout mice [50]. The present work also demonstrated that either pharmacological blockade of $\mu$ Rs (Fig. 1b) or knockout (whether non-selective or selective) of $\mu \mathrm{R}$ (Supplementary Figure 8) did not alter memory retrieval in the MWM task under unstressed conditions. In the case of the stressed condition, we observed that endogenous activation 
of $\mu$ Rs functionally damaged memory recall during acute stress. It has been shown that the involved $\mu$ Rs are localized exclusively at the terminals and somata of GABAergic inhibitory neurons and coupled with inhibitory $G$ proteins. Activation of those $\mu$ Rs decreases GABA release presynaptically by a $\mathrm{G}$ protein-mediated inhibition process; [51] therefore, mIPSCs and sIPSCs recorded in pyramidal neurons innervated by those GABAergic neurons were reduced (Fig. 3). Meanwhile, binding with EOPs induces rapid phosphorylation of $\mu$ Rs on the intracellular C-terminal domains, which subsequently results in endocytosis of $\mu \mathrm{Rs}$ in a $\beta$-arrestin-mediated manner within approximately 30 min [52]. Rapid phosphorylation of hippocampal $\mu \mathrm{Rs}$ at the position of Ser375 followed by a reduction in the abundance of cell-surface $\mu \mathrm{Rs}$, which were putatively elicited by Met-enkephalin, was observed in the present study (Fig. 1c). The phosphorylation and internalization of $\mu \mathrm{Rs}$ induced by stress blunt $\mu \mathrm{R}$ function and thus eliminate the DAMGO-induced inhibition of GABAergic transmission (Fig. 4b).

GABAergic interneurons are essential in balancing the excitation and inhibition signals in the brain. Disinhibition of hippocampal pyramidal neurons caused by depression of GABAergic neurons has been implicated in memory impairments [21] and psychiatric disorders [53]. Selective reduction in functional inhibitory synapses or GABA depletion in the dorsal hippocampus impairs spatial learning and memory [54]. Consistently, it was observed in the present work that blockade or over-activation of hippocampal $\mathrm{GABA}_{\mathrm{A}}$ receptors impaired memory retrieval (Fig. 5a, b). In agreement with a previous study that showed that the GABA release probability is reduced in the hippocampus of stress-susceptible animals [55], our study revealed that in response to acute stress, the phasic inhibitory currents mediated by the intrasynaptic $\mathrm{GABA}_{\mathrm{A}}$ receptors (containing $\alpha 1, \alpha 2$ and/or $\gamma$-subunits) were specifically suppressed. GABAergic inhibitory transmission in the CA1 field was depressed as a result of activation of $\mu \mathrm{Rs}$ on GABAergic neurons (Fig. 3). We concluded that the reduction in phasic inhibitory currents is associated with stress-induced retrieval impairment because putatively upregulating the phasic component alone by coadministration of muscimol and L-655,708 prevented memory impairment after EP stress (Fig. 5d). GABAergic signalling can also be altered by chronic stress [27, 55-57] and thus interrupt the normal E/I balance in memory-related circuits in the brain. However, chronic stress simultaneously alters tonic inhibition and phasic inhibition [57-59]. How chronic stress extends its effects on GABAergic signalling from presynaptic to postsynaptic sites and from intrasynaptic to extrasynaptic $\mathrm{GABA}_{\mathrm{A}}$ receptors is still unknown. A possible explanation is that acute stress preferentially alters GABA release by activating $\mu R_{G A B A}$, whereas the influence of chronic stress involves a long-lasting modulation of $\mathrm{GABA}_{\mathrm{A}}$ receptors enacted by changing the distribution of their subunit compositions [60], altering their allosteric binding sites [60], and even disturbing astrocytemediated GABA uptake and degradation [61].

It is well known that memory retrieval depends both on individual neuronal firing behaviour and the synchronous oscillations of spatially distributed neurons [62]. A dynamic E/I balance is essential for maintaining neuronal firing behaviour and the oscillatory patterns of hippocampal neurons [63]. Breaking the E/I balance in either direction will damage memory retrieval by altering the firing threshold [64] or shifting the patterns of neural oscillation in the neuronal populations related to memory retrieval [65]. As observed in the present experiment, memory retrieval could be impaired by both blockade of the GABAergic receptors and activation of the receptors with high doses of agonists. During acute stress, non-selective disinhibition of hippocampal pyramidal neurons may change the firing rates of individual neurons and the oscillation patterns of neuronal populations, resulting in impairment of memory retrieval. In this case, muscimol application at a proper dosage might non-selectively neutralize the effects of stress on GABAergic inhibition and thereby rescue the impairment of memory retrieval.

It has been demonstrated that stress can impair memory retrieval by modulating glutamatergic synaptic plasticity in the hippocampus by inhibiting LTP induction or facilitating LTD expression [4-8]. A number of previous studies have observed that acute stress resets the thresholds for LTP and/ or LTD, without an obvious effect on the basal excitatory synaptic efficacy in the CA1 region [7, 39, 66, 67]. Elevated corticosteroid hormones during stress facilitate LTD and suppress LTP, probably by regulating membrane trafficking of GluR2-containing AMPARs [68] and GluN2Bcontaining NMDARs [69], which can consequently lead to memory-retrieval impairments $[4,5,7]$. In addition to the corticosteroid-mediated modulation of synaptic plasticity, the present study clearly showed a new pathway in which acute stress depresses GABAergic inhibitory transmission to CA1 pyramidal neurons through endogenous activation of $\mu \mathrm{R}_{\mathrm{GABA}}$, resulting in $\mathrm{E} / \mathrm{I}$ imbalance in the hippocampus and thereby impairing memory retrieval. Intriguingly, our additional data [70] revealed that EP stress facilitates LTD induced by low-frequency stimulation (LFS, 900 pulses at $3 \mathrm{~Hz}$ ) at the Schaffer collateral/commissural-CA1 synapses in mice and that this stress facilitated LFS-LTD depends on the activation of $\mu \mathrm{R}_{\mathrm{GABA}}$ during stress (the facilitation of LTD can be abolished by naloxone administration before stress and is absent in mice lacking $\left.\mu \mathrm{R}_{\mathrm{GABA}}\right)$. Facilitation of LTD suggests that activation of $\mu R_{G A B A}$ lowers the threshold of LTD induction (depolarization of pyramidal neurons removes shunting and hyperpolarizing effects on 
NMDAR activation) [71]. Thus, endogenous activation of $\mu \mathrm{R}_{\mathrm{GABA}}$ by EP stress may not only disturb $\mathrm{E} / \mathrm{I}$ balance but also modulate synaptic plasticity, both of which are associated with hippocampus-based memory retrieval [72, 73]. These results suggest that corticosterone-mediated modulation of synaptic plasticity is not the sole pathway of memory-retrieval impairments induced by stressful events $[9,74,75]$ (Fig. 5e). Blocking this $\mu$ R-mediated depression of local inhibitory transmission reversed the memory impairment but had no effects on the elevation of corticosterone induced by stress (Fig. 1g), implying that in response to acute stress, this $\mu \mathrm{R}$-mediated depression of local inhibitory transmission is sufficient to cause memoryretrieval impairment. However, the possible effects of stress hormones on the secretion of EOPs and activation of the $\mu \mathrm{R}$-mediated depression of inhibitory transmission in the hippocampus remain to be addressed in future.

Acknowledgements This work was supported by grants from National Natural Science Foundation of China No. (No. 81171264 to ZL, 31501864 to YQ and 81771227 to JH); the work was also supported by China Postdoctoral Science Foundation funded project (No. 2016M592744 to MS); and the Fundamental Research Funds for the Central Universities (No. GK201603117 to MS, GK201702006 to YT). Aside from the listed authors, we thank Dr Yihui Liu, Drs Qiaohua Zheng, and Dr Weiping Hu (MOE Key Laboratory of Modern Teaching Technology, Shaanxi Normal University, Xi'an, China) for help with data analysis (YL), morphological data collection (QZ), suggestions on the manuscript (WH). We also thank Dr Xia Zhang (Institute of Mental Health Research and Departments of Psychiatry and Cellular and Molecular Medicine, University of Ottawa, Ottawa, Ontario, Canada) for helpful suggestions on revision.

\section{Compliance with ethical standards}

Conflict of interest The authors declare that they have no conflict of interest.

Publisher's note: Springer Nature remains neutral with regard to jurisdictional claims in published maps and institutional affiliations.

Open Access This article is licensed under a Creative Commons Attribution 4.0 International License, which permits use, sharing, adaptation, distribution and reproduction in any medium or format, as long as you give appropriate credit to the original author(s) and the source, provide a link to the Creative Commons license, and indicate if changes were made. The images or other third party material in this article are included in the article's Creative Commons license, unless indicated otherwise in a credit line to the material. If material is not included in the article's Creative Commons license and your intended use is not permitted by statutory regulation or exceeds the permitted use, you will need to obtain permission directly from the copyright holder. To view a copy of this license, visit http://creativecommons. org/licenses/by/4.0/.

\section{References}

1. Schwabe L, Wolf OT, Oitzl MS. Memory formation under stress: quantity and quality. Neurosci Biobehav Rev. 2010;34:584-91.
2. Joels M, Pu Z, Wiegert O, Oitzl MS, Krugers HJ. Learning under stress: how does it work? Trends Cogn Sci. 2006;10:152-8.

3. de Quervain DJ, Roozendaal B, McGaugh JL. Stress and glucocorticoids impair retrieval of long-term spatial memory. Nature. 1998;394:787-90.

4. Wong TP, Howland JG, Robillard JM, Ge Y, Yu W, Titterness $\mathrm{AK}$, et al. Hippocampal long-term depression mediates acute stress-induced spatial memory retrieval impairment. Proc Natl Acad Sci USA 2007;104:11471-6.

5. Kim JJ, Foy MR, Thompson RF. Behavioral stress modifies hippocampal plasticity through N-methyl-D-aspartate receptor activation. Proc Natl Acad Sci USA 1996;93:4750-3.

6. Xu L, Anwyl R, Rowan MJ. Behavioural stress facilitates the induction of long-term depression in the hippocampus. Nature. 1997;387:497-500.

7. Xu L, Holscher C, Anwyl R, Rowan MJ. Glucocorticoid receptor and protein/RNA synthesis-dependent mechanisms underlie the control of synaptic plasticity by stress. Proc Natl Acad Sci USA 1998;95:3204-8.

8. Cazakoff BN, Johnson KJ, Howland JG. Converging effects of acute stress on spatial and recognition memory in rodents: a review of recent behavioural and pharmacological findings. Prog Neuropsychopharmacol Biol Psychiatry. 2010;34:733-41.

9. Shields GS, Sazma MA, McCullough AM, Yonelinas AP. The effects of acute stress on episodic memory: a meta-analysis and integrative review. Psychol Bull. 2017;143:636-75.

10. Valentino RJ, Van Bockstaele E. Convergent regulation of locus coeruleus activity as an adaptive response to stress. Eur J Pharmacol. 2008;583:194-203.

11. Bali A, Randhawa PK, Jaggi AS. Stress and opioids: role of opioids in modulating stress-related behavior and effect of stress on morphine conditioned place preference. Neurosci Biobehav Rev. 2015;51:138-50.

12. Valentino RJ, Van Bockstaele E. Endogenous opioids: the downside of opposing stress. Neurobiol Stress. 2015;1:23-32.

13. Kalivas PW, Volkow ND. The neural basis of addiction: a pathology of motivation and choice. Am J Psychiatry. 2005;162:1403-13.

14. Fichna J, Janecka A, Costentin J, Do Rego JC. The endomorphin system and its evolving neurophysiological role. Pharmacol Rev. 2007;59:88-123.

15. Gusev PA, Cui C, Alkon DL, Gubin AN. Topography of Arc/ Arg3.1 mRNA expression in the dorsal and ventral hippocampus induced by recent and remote spatial memory recall: dissociation of CA3 and CA1 activation. J Neurosci. 2005;25:9384-97.

16. Drake CT, Milner TA. Mu opioid receptors are in discrete hippocampal interneuron subpopulations. Hippocampus. 2002;12:119-36.

17. Simmons ML, Chavkin C. Endogenous opioid regulation of hippocampal function. Int Rev Neurobiol. 1996;39:145-96.

18. Dacher M, Nugent FS. Opiates and plasticity. Neuropharmacology. 2011;61:1088-96.

19. Krook-Magnuson E, Luu L, Lee SH, Varga C, Soltesz I. Ivy and neurogliaform interneurons are a major target of mu-opioid receptor modulation. J Neurosci. 2011;31:14861-70.

20. Bodnar RJ. Endogenous opiates and behavior: 2015. Peptides. 2017;88:126-88.

21. Klyachko VA, Stevens CF. Excitatory and feed-forward inhibitory hippocampal synapses work synergistically as an adaptive filter of natural spike trains. PLoS Biol. 2006;4:e207.

22. Chen C, Dickendesher TL, Oyama F, Miyazaki H, Nukina N, Isom LL. Floxed allele for conditional inactivation of the voltage-gated sodium channel beta1 subunit Scn1b. Genesis. 2007;45:547-53.

23. Hirrlinger PG, Scheller A, Braun C, Hirrlinger J, Kirchhoff F. Temporal control of gene recombination in astrocytes by transgenic expression of the tamoxifen-inducible DNA recombinase variant CreERT2. Glia. 2006;54:11-20. 
24. Zhong H, Tong L, Gu N, Gao F, Lu Y, Xie RG, et al. Endocannabinoid signaling in hypothalamic circuits regulates arousal from general anesthesia in mice. J Clin Invest. 2017;127:2295-309.

25. Loweth JA, Scheyer AF, Milovanovic M, LaCrosse AL, FloresBarrera E, Werner CT, et al. Synaptic depression via mGluR1 positive allosteric modulation suppresses cue-induced cocaine craving. Nat Neurosci. 2014;17:73-80.

26. El Kouhen R, Burd AL, Erickson-Herbrandson LJ, Chang CY, Law PY, Loh HH. Phosphorylation of Ser363, Thr370, and Ser375 residues within the carboxyl tail differentially regulates mu-opioid receptor internalization. J Biol Chem. 2001;276:12774-80.

27. Raynor K, Kong H, Chen Y, Yasuda K, Yu L, Bell GI, et al. Pharmacological characterization of the cloned kappa-, delta-, and mu-opioid receptors. Mol Pharmacol. 1994;45:330-4.

28. Shimoyama M, Toyama S, Tagaito Y, Shimoyama N. Endogenous endomorphin-2 contributes to spinal k-opioid antinociception. Pharmacology. 2012;89:145-8.

29. Gong N, Xiao Q, Zhu B, Zhang CY, Wang YC, Fan H, et al. Activation of spinal glucagon-like peptide-1 receptors specifically suppresses pain hypersensitivity. J Neurosci. 2014;34:5322-34.

30. Nam MH, Han KS, Lee J, Bae JY, An H, Park S, et al. Expression of micro-Opioid Receptor in CA1 Hippocampal Astrocytes. Exp Neurobiol. 2018;27:120-8.

31. Schnell SA, Wessendorf MW. Coexpression of the mu-opioid receptor splice variant MOR1C and the vesicular glutamate transporter 2 (VGLUT2) in rat central nervous system. J Comp Neurol. 2008;508:542-64.

32. Mody I, Pearce RA. Diversity of inhibitory neurotransmission through GABA(A) receptors. Trends Neurosci. 2004;27:569-75.

33. Caraiscos VB, Elliott EM, You-Ten KE, Cheng VY, Belelli D, Newell JG, et al. Tonic inhibition in mouse hippocampal CA1 pyramidal neurons is mediated by alpha5 subunit-containing gamma-aminobutyric acid type A receptors. Proc Natl Acad Sci U S A. 2004;101:3662-7.

34. Martin LJ, Zurek AA, MacDonald JF, Roder JC, Jackson MF, Orser BA. Alpha5GABAA receptor activity sets the threshold for long-term potentiation and constrains hippocampus-dependent memory. J Neurosci. 2010;30:5269-82.

35. Scholfield CN. Baclofen blocks postsynaptic inhibition but not the effect of muscimol in the olfactory cortex. Br J Pharmacol. 1983;78:79-84.

36. Nakagawa T, Wakamori M, Shirasaki T, Nakaye T, Akaike N. gamma-Aminobutyric acid-induced response in acutely isolated nucleus solitarii neurons of the rat. Am J Physiol. 1991;260(4 Pt 1):C745-749.

37. Wang Y, Romani S, Lustig B, Leonardo A, Pastalkova E. Theta sequences are essential for internally generated hippocampal firing fields. Nat Neurosci. 2015;18:282-8.

38. Matus-Amat P, Higgins EA, Barrientos RM, Rudy JW. The role of the dorsal hippocampus in the acquisition and retrieval of context memory representations. J Neurosci. 2004;24:2431-9.

39. Macdougall MJ, Howland JG. Acute stress and hippocampal output: exploring dorsal CA1 and subicular synaptic plasticity simultaneously in anesthetized rats. Physiol Rep. 2013;1:e00035.

40. Tsigos C, Kyrou I, Kassi E, Chrousos GP. Stress, endocrine physiology and pathophysiology. In: De Groot LJ, Chrousos G, Dungan K, Feingold KR, Grossman A, Hershman JM et al., (eds) Endotext [Internet]. South Dartmouth: MDText.com, Inc.; 2000.

41. Charmandari E, Tsigos C, Chrousos G. Endocrinology of the stress response. Annu Rev Physiol. 2005;67:259-84.

42. Fuentealba P, Tomioka R, Dalezios Y, Marton LF, Studer M, Rockland $\mathrm{K}$, et al. Rhythmically active enkephalin-expressing GABAergic cells in the CA1 area of the hippocampus project to the subiculum and preferentially innervate interneurons. J Neurosci. 2008;28:10017-22.
43. Drolet G, Dumont EC, Gosselin I, Kinkead R, Laforest S, Trottier JF. Role of endogenous opioid system in the regulation of the stress response. Prog Neuropsychopharmacol Biol Psychiatry. 2001;25:729-41.

44. Li W, Papilloud A, Lozano-Montes L, Zhao N, Ye X, Zhang X, et al. Stress impacts the regulation neuropeptides in the rat hippocampus and prefrontal cortex. Proteomics. 2018;18:e1700408.

45. Van't Veer A, Carlezon WA Jr.. Role of kappa-opioid receptors in stress and anxiety-related behavior. Psychopharmacology. 2013;229:435-52.

46. Land BB, Bruchas MR, Lemos JC, Xu M, Melief EJ, Chavkin C. The dysphoric component of stress is encoded by activation of the dynorphin kappa-opioid system. J Neurosci. 2008;28:407-14.

47. Commons KG. Translocation of presynaptic delta opioid receptors in the ventrolateral periaqueductal gray after swim stress. J Comp Neurol. 2003;464:197-207.

48. Gonzales KL, Chapleau JD, Pierce JP, Kelter DT, Williams TJ, Torres-Reveron A, et al. The influences of reproductive status and acute stress on the levels of phosphorylated mu opioid receptor immunoreactivity in rat hippocampus. Front Endocrinol (Lausanne). 2011;2:00018.

49. Zhu F, Yan CX, Zhao Y, Zhao Y, Li PP, Li SB. Effects of pretraining morphine on spatial memory acquisition and retrieval in mice. Physiol Behav. 2011;104:754-60.

50. Lubbers ME, van den Bos R, Spruijt BM. Mu opioid receptor knockout mice in the Morris Water Maze: a learning or motivation deficit? Behav Brain Res. 2007;180:107-11.

51. Capogna M, Gahwiler BH, Thompson SM. Mechanism of muopioid receptor-mediated presynaptic inhibition in the rat hippocampus in vitro. J Physiol. 1993;470:539-58.

52. Williams JT, Ingram SL, Henderson G, Chavkin C, von Zastrow M, Schulz S, et al. Regulation of mu-opioid receptors: desensitization, phosphorylation, internalization, and tolerance. Pharmacol Rev. 2013;65:223-54.

53. Marin O. Interneuron dysfunction in psychiatric disorders. Nat Rev Neurosci. 2012;13:107-20.

54. Lipina TV, Prasad T, Yokomaku D, Luo L, Connor SA, Kawabe $\mathrm{H}$, et al. Cognitive deficits in calsyntenin-2-deficient mice associated with reduced GABAergic transmission. Neuropsychopharmacology. 2016;41:802-10.

55. Nieto-Gonzalez JL, Holm MM, Vardya I, Christensen T, Wiborg O, Jensen K. Presynaptic plasticity as a hallmark of rat stress susceptibility and antidepressant response. PLoS ONE. 2015;10: e0119993.

56. Serra M, Pisu MG, Littera M, Papi G, Sanna E, Tuveri F, et al. Social isolation-induced decreases in both the abundance of neuroactive steroids and $\mathrm{GABA}(\mathrm{A})$ receptor function in rat brain. J Neurochem. 2000;75:732-40.

57. Holm MM, Nieto-Gonzalez JL, Vardya I, Henningsen K, Jayatissa MN, Wiborg O, et al. Hippocampal GABAergic dysfunction in a rat chronic mild stress model of depression. Hippocampus. 2011;21:422-33.

58. Lee V, MacKenzie G, Hooper A, Maguire J. Reduced tonic inhibition in the dentate gyrus contributes to chronic stressinduced impairments in learning and memory. Hippocampus. 2016;26:1276-90.

59. MacKenzie G, Maguire J. Chronic stress shifts the GABA reversal potential in the hippocampus and increases seizure susceptibility. Epilepsy Res. 2015;109:13-27.

60. Hsu FC, Zhang GJ, Raol YS, Valentino RJ, Coulter DA, BrooksKayal AR. Repeated neonatal handling with maternal separation permanently alters hippocampal GABAA receptors and behavioral stress responses. Proc Natl Acad Sci USA 2003;100:12213-8.

61. Albrecht A, Ivens S, Papageorgiou IE, Caliskan G, Saiepour N, Bruck W, et al. Shifts in excitatory/inhibitory balance by juvenile 
stress: a role for neuron-astrocyte interaction in the dentate gyrus. Glia. 2016;64:911-22.

62. Watrous AJ, Fell J, Ekstrom AD, Axmacher N. More than spikes: common oscillatory mechanisms for content specific neural representations during perception and memory. Curr Opin Neurobiol. 2015;31:33-39.

63. Lamsa K, Heeroma JH, Kullmann DM. Hebbian LTP in feedforward inhibitory interneurons and the temporal fidelity of input discrimination. Nat Neurosci. 2005;8:916-24.

64. Landau ID, Egger R, Dercksen VJ, Oberlaender M, Sompolinsky H. The Impact of Structural Heterogeneity on Excitation-Inhibition Balance in Cortical Networks. Neuron. 2016;92:1106-21.

65. Hanson JE, Weber M, Meilandt WJ, Wu T, Luu T, Deng L, et al. GluN2B antagonism affects interneurons and leads to immediate and persistent changes in synaptic plasticity, oscillations, and behavior. Neuropsychopharmacology. 2013;38:1221-33.

66. Chaouloff F, Hemar A, Manzoni O. Acute stress facilitates hippocampal CA1 metabotropic glutamate receptor-dependent longterm depression. J Neurosci. 2007;27:7130-5.

67. Huang CC, Yang CH, Hsu KS. Do stress and long-term potentiation share the same molecular mechanisms? Mol Neurobiol. 2005;32:223-35.

68. Groc L, Choquet D, Chaouloff F. The stress hormone corticosterone conditions AMPAR surface trafficking and synaptic potentiation. Nat Neurosci. 2008;11:868-70.
69. Mikasova L, Xiong H, Kerkhofs A, Bouchet D, Krugers HJ, Groc L. Stress hormone rapidly tunes synaptic NMDA receptor through membrane dynamics and mineralocorticoid signalling. Sci Rep. 2017;7:8053.

70. Fan KM, Qiu LJ, Ma N, Du YN, Qian ZQ, Wei CL, et al. Acute stress facilitates LTD induction at glutamatergic synapses in the hippocampal CA1 region by activating mu-opioid receptors on GABAergic neurons. Front Neurosci. 2019;13:71.

71. Wagner JJ, Alger BE. GABAergic and developmental influences on homosynaptic LTD and depotentiation in rat hippocampus. J Neurosci. 1995;15:1577-86.

72. Colgin LL, Denninger T, Fyhn M, Hafting T, Bonnevie T, Jensen $\mathrm{O}$, et al. Frequency of gamma oscillations routes flow of information in the hippocampus. Nature. 2009;462:353-7.

73. Ruediger S, Vittori C, Bednarek E, Genoud C, Strata P, Sacchetti $\mathrm{B}$, et al. Learning-related feedforward inhibitory connectivity growth required for memory precision. Nature. 2011;473:514-8.

74. Dorey R, Pierard C, Shinkaruk S, Tronche C, Chauveau F, Baudonnat $\mathrm{M}$, et al. Membrane mineralocorticoid but not glucocorticoid receptors of the dorsal hippocampus mediate the rapid effects of corticosterone on memory retrieval. Neuropsychopharmacology. 2011;36:2639-49.

75. Shields GS, Sazma MA, Yonelinas AP. The effects of acute stress on core executive functions: a meta-analysis and comparison with cortisol. Neurosci Biobehav Rev. 2016;68:651-68. 